\title{
On the Welfare Benefits of an International Currency
}

\author{
Prakash Kannan* \\ Research Department \\ International Monetary Fund
}

October 2006

\begin{abstract}
Is it beneficial for a country's currency to be used internationally? And, if so, can we quantify the benefit? Over the last 50 years or so, the US dollar has held the dominant position as the main medium of exchange in international transactions - i.e., as the dominant international currency. Since the emergence of the euro as a viable alternative international currency, there has been great interest in the consequences of a transfer of the dollar's premier international role to the euro. Building on recent advancements in the literature on search models of money, this paper presents a novel model-based approach towards assessing the welfare benefits associated with the international use of a country's currency. Apart from the familiar benefits associated with seignorage, the model highlights a new channel that operates through the terms of trade. In the calibration exercise carried out in this paper, the benefits originating from this channel are quantitatively significant. The welfare gain for the Euro area in having the euro internationally used ranges from $1.7 \%$ to $2.1 \%$ of consumption depending on relative inflation rates. Of this gain, the benefits accruing to seignorage are on the order of $0.5 \%$ to $0.7 \%$. The rest of the world is not indifferent as to which currency circulates as the dominant international currency. Conditional on their currency not being used internationally, their preference is for the dominant international currency to be the one with the lowest inflation rate.
\end{abstract}

Keywords: International Currency, Search models of money JEL Classifications: E40, F33

*Email: pkannan@imf.org. Corresponding address: 700 19th Street, NW, Washington, D.C. 20431. I would like to thank Mick Devereux, Robert Hall, Emeric Henry, Romans Pancs, Esteban Rossi-Hansberg, Michele Tertilt, Mark Wright, Joanne Yoong and especially Pete Klenow for valuable comments on this and earlier versions of this paper. The views expressed in this paper are solely mine and do not necessarily reflect those of the International Monetary Fund. 


\section{Introduction}

National monies, though often a symbol of national pride, are in reality an inconvenience. From the viewpoint of the occasional tourist right up to the multinational corporation, dealing in different currencies with different countries has real costs. In cross-border transactions, however, while there exist almost as many currencies as there are countries, economic forces have led to the use of only a handful of currencies. Over the last 60 years or so, the US dollar has held the dominant position as the main currency of trade invoicing. The share of world trade denominated in US dollars far exceeds the share of the US in world trade. In Asia, the share of dollar-denominated trade ranges from $52 \%$ to $84 \%$ across countries, while similar estimates for EU countries, for trade outside the EU area, are in the range of $20 \%$ to $71 \%$. $^{1}$

Some consensus has emerged on the factors underlying the choice of which currency is used as the medium of exchange in international transactions - what we term an "international currency". ${ }^{2}$ The size of the issuing country, its share of world trade and the stability of the currency's value are some of the key factors that have emerged from the analysis in this literature. ${ }^{3}$ The mapping of these factors into outcomes, however, is not one-toone. A recurrent theme in the study of international currencies is the presence of network externalities. ${ }^{4}$ The benefit that agents derive from using a particular currency increases with the number of other agents who use it. These network externalities introduce multiple equilibria and inertia in the choice of an international currency. ${ }^{5}$

From a normative perspective, however, the question of the welfare benefit of international currencies has received less attention. Is it beneficial for a country's currency to be used internationally? And, if so, can we quantify the benefit? These questions are not merely of academic interest. The emergence of the euro as a viable international currency has sparked great interest as to whether the US dollar's position as the dominant inter-

\footnotetext{
${ }^{1}$ See Goldberg and Tille (2005).

${ }^{2}$ Note that this use of the term is different from the notion of a "vehicle currency". For contributions in that literature see Hartmann (1997) and Devereux and Shi (2005).

${ }^{3}$ For early contributions, see Kindleberger (1981), McKinnon (1979), and Krugman (1984).

${ }^{4}$ These network externalities have been elaborated upon in more recent papers on international currencies such as Dowd and Greenaway (1993), Matsuyama, Kiyotaki and Matsui (1993), Krugman (1980), Rey (2001), and Wright and Trejos $(1996,2001)$.

${ }^{5}$ See Chinn and Frankel (2005) and Kannan (2006).
} 
national currency will be transferred to the euro, bringing to mind the mid-20th century transition from the pound sterling to the dollar as the key international currency. Portes and Rey (1998) make an attempt to measure the welfare impact of such a transition. They estimate that the direct and indirect seignorage benefits that the US gains by having its currency circulate abroad is roughly $0.2 \%$ of GDP. Should the euro become the dominant international currency as a result of reducing the transaction costs in its financial markets, they estimate an additional benefit of $0.2 \%$ of GDP accruing to the Euro area. ${ }^{6}$

In this paper, we present a novel model-based approach in assessing the benefits of an international currency. The modeling approach taken in this paper draws on recent developments in the literature on search models of money which originated in the seminal papers of Kiyotaki and Wright $(1989,1993)$. In particular, the model builds upon the framework presented in Lagos and Wright (2005). While Lagos and Wright analyze monetary equilibria in a closed-economy setting, this paper looks at equilibria in an open-economy framework. Agents meet and trade with other agents domestically as well as internationally. The interaction occurs through both centralized markets where homogenous goods are traded as well as decentralized markets where differentiated goods are traded.

In the baseline version of the model, exporters optimally choose which currencies to invoice their trade in. A currency become "international" if sellers decide to use it to invoice their international transactions. The factors that influence the choice of the seller are threefold: the behavior of other sellers, the relative size of the trading partner and the inflation rate of the currency. In common with the existing literature on international currencies as mentioned earlier, the behavior of other sellers in this model introduces an externality into the invoicing decision of a particular seller. The surplus that accrues to invoicing in a given currency increases if other sellers invoice in that currency too. The behavior of other sellers, however, cease to matter in trades with large countries. When trading with a large enough country, it becomes optimal to always invoice in the domestic currency of the buyer regardless of what other agents are doing. In this model, therefore, the size of a country also plays a role in determining whether its currency is used internationally or not. The resulting model is analytically tractable for the same reasons as Lagos and Wright, and thus

\footnotetext{
${ }^{6}$ Other attempts at measuring the welfare benefit of an international currency include Cohen (1971). Cohen undertakes a detailed exercise in computing the monetary value of the benefit to the international use of the pound sterling in financial markets as well as well as trade.
} 
facilitates the computation of equilibrium values and the analysis of welfare. ${ }^{7}$

The model features two channels through which a gain in welfare can occur for the residents of the issuing country when their currency is used in international transactions. The first channel is via seignorage revenues. The external demand for real balances in the domestic currency leads to a transfer of resources to the issuing country. The benefit obtained through seignorage is increasing with the rate of inflation. The country that has an internationally used currency, therefore, has the ability to levy an inflation tax on foreign residents. The second channel, which has not received any attention in the literature, is one that operates through trade. As more people use the domestic currency, its value in terms of the quantity of goods that can be purchased for a unit of the currency increases. In other words, the issuing country experiences a terms-of-trade improvement.

The intuition for how the terms-of-trade channel operates is as follows. As in most monetary models, agents in this model have to decide on how to allocate resources between present consumption and real money balances. If every transaction that the agent can expect to conduct in the next period is carried out in the same currency, then the decision is made based on the rate of inflation and the share of the surplus the buyer expects to get in each transaction. ${ }^{8}$ The higher the rate of inflation, the lower the money balances held by the agent as she would prefer to divert more resources towards present consumption. The same effect would occur if she got a lower share of the surplus from transactions in the decentralized market. If instead, different transactions that the agent expects to carry out next period are invoiced in different currencies, the agent has now another dimension to her choice. She now has to allocate resources between present consumption, balances in the domestic currency and balances in a foreign currency. If the inflation rates and the share of the surplus are the same for both currencies, the agent will hold balances in each currency as a function of the proportion of transactions she expects to carry out in that currency next period. Since she now has to decide between multiple currencies, the fraction of her resources that she invests in balances in any one currency will be less than the fraction of resources she would have invested had all her next-period trade been conducted in one

\footnotetext{
${ }^{7}$ The complications associated with search models that had divisible holdings of money came from the endogenous distribution of money holdings. The technical contribution of Lagos and Wright was to introduce a framework where the distribution of money holdings is degenerate at the end of every period.

${ }^{8}$ The influence of the buyer's share of the surplus in each transaction on the decision regarding how much money balances to hold was a novel contribution of Lagos and Wright (2005).
} 
currency. The surplus in any trade, however, is increasing in the amount of real balances brought into the trade. ${ }^{9}$ Consequently, compared to an equilibrium where the agent has to invest in multiple currencies, the value of the domestic currency in an equilibrium where the agent's currency is accepted everywhere is higher.

The model developed in this paper allows for a straightforward calibration and thus a quantification of the welfare effects described above. An important set of parameters in the model are "meeting" parameters, which are assoicated with the probabilities that an agent meets another agent either from her own country or from another country. In the calibration exercise carried out in this paper, we take advantage of a natural interpretation of these parameters by mapping them to bilateral trade shares. We partition the world into three groups: the US, the Euro area and the rest of the world. We compare consumption equivalent welfare changes across three equilibria. The first is where the US dollar is the sole medium of exchange used in international transactions. The second is one where there are two international currencies, the dollar and the euro. Transactions with the Euro area are carried out in euros while transactions with the US are done in dollars. Transactions with the rest of the world, however, are still conducted in dollars. In the third equilibrium studied, the international use of the euro increases as now trade with the rest of the world is also carried out in euros.

The welfare benefit for the Euro area in having their currency internationally used ranges from $1.7 \%$ to $2.1 \%$ of consumption depending on the inflation rates in other parts of the world. Of this gain, the benefits accruing to seignorage are on the order of $0.5 \%$ to $0.7 \%$. What is a gain for the Euro area is a loss for the US. The net gain, however, is not zero since inflation rates and country sizes differ. An interesting result obtained is that when inflation rates differ across countries, the rest of the world is not indifferent as to which currency circulates as the dominant international currency. Conditional on their currency not being used internationally, the preference for the rest of the world is for the dominant international currency to be the one with the lowest inflation rate.

In the baseline model, agents were only allowed to transact in the currency of invoice. We extend the model in the last section of this paper to allow agents to use any currency

\footnotetext{
${ }^{9}$ The surplus is increasing since for all monetary equilibria in the model, agents will hold less than the efficient quantity of real balances as long as inflation is higher than that prescribed by the Friedman Rule and the buyer's bargaining power is less than one.
} 
in their portfolio. We introduce, however, a transaction cost for using currencies that are not the currency of invoice so that the individual identities of the currencies still matter. Transaction costs have two effects in this model. Apart from the direct effect of reducing welfare anytime a non-invoice currency is used, they also have an indirect effect in terms of the allocation of resources towards money balances. Higher transaction costs divert resources to present consumption and away from money balances as it reduces the value of the money in the next period. As we would expect, the magnitude of the welfare changes in this model is increasing with the size of the transaction costs. However, even at a transaction cost of $10 \%$, the magnitudes are much smaller than in the baseline model. The welfare benefit for the Euro area in having the euro internationally used ranges from $0.03 \%$ to $0.26 \%$ of consumption depending on the level of the transaction costs.

The paper is organized as follows: Section 2 and 3 describe the general environment and the decision problems faced by the agents in the model. Section 4 discusses the specific details of the baseline model. Section 5 provides a quantitative estimate of the welfare impact of a change in the international use of a currency. Section 6 presents the extension of the baseline model where all currencies can be used in any given transaction. Quantitative estimates of the welfare impact are then calculated. Section 7 provides a discussion of the results and concludes. An appendix contains the complete proofs of all the lemmas and propositions referenced in the text and also includes some robustness checks.

\section{Environment}

There are 3 countries in the model, $A, B$ and $C$, each with their own respective currencies, $\alpha, \beta$ and $\gamma$. In each country $i$, there is a continuum of infinitely lived agents of measure $n_{i}$, with $\sum_{i} n_{i}=1$. Time is discrete in this model.

\subsection{Goods and Technology}

Each period is divided into two subperiods. During the first subperiod, agents from all countries participate in a decentralized market where they randomly meet agents from their own country or from another country. The probability of an agent from country $i$ meeting 
an agent from country $j$ is $\mu_{i j}{ }^{10}$ Only one bilateral meeting per agent occurs during this sub-period. In the second subperiod, agents trade in a centralized market.

There are two types of commodities that are produced: a single type of homogenous good and a set of differentiated goods. All agents consume the homogenous good, but each agent derives utility from only a subset of differentiated goods. Homogenous goods are produced in the centralized market, whereas differentiated goods are produced by individual agents in the decentralized market. Each agent has a technology that allows her to produce only one type of differentiated good, which is not a member of the set of differentiated goods that she derives utility from. Both homogenous goods and differentiated goods are assumed to be perishable and thus have to be consumed immediately. ${ }^{11}$

The features embedded in the setup described above provide the motivation for trade in the decentralized market and generate an environment where money is essential to conduct transactions. The assumption that agents cannot produce the type of differentiated good that they derive utility from makes trade potentially welfare enhancing. A "single coincidence of wants", where either party in a bilateral meeting desires the good produced by the other, occurs with probability $\sigma$. Meanwhile, the anonymous nature of the meetings between agents rules out any form of credit arrangements, making money essential to facilitate transactions between agents (see Kocherlakota (1998) and Wallace (2001)). We assume that there is no double coincidence of wants in the decentralized economy, and as such, there is no barter trade.

\subsection{Preferences}

Agents have preferences for differentiated goods and homogenous goods, $u(q)$ and $U(x)$, that are $C^{3}$, strictly increasing and strictly concave. We also assume that $u(0)=0$ and $\lim _{q \rightarrow \infty} u^{\prime}(q)=\infty$. The variables $q$ and $x$ refer to the quantities of the differentiated good and the homogenous good that are consumed. There is a cost in utility terms associated with the production of both homogenous goods and differentiated goods, $v(y)$ and $c(q)$.

\footnotetext{
${ }^{10} \mu_{i j}$ is not independent from $\mu_{j i}$ since the total measure of meetings between agents from both countries have to match up: $n_{i} \mu_{i j}=n_{j} \mu_{j i}$.

${ }^{11}$ The perishability assumption is not crucial. Introducing production and the ability to store the homogenous good in the form of capital, along the lines of Aruoba and Wright (2003), will not change any of the results as long as claims on capital are not used for transactions.
} 
In this paper, we will assume that the functional form for both the cost functions are linear, i.e. $v(y)=y$ and $c(q)=q$. The functional form assumption for the disutility associated with producing the differentiated good is purely for the convenience of obtaining simplified expressions in most cases. The linearity assumption for the cost of producing the homogenous good, however, plays a more significant role in the setup which will become evident later. Lastly, agents discount between periods with a discount factor of $\delta$.

\subsection{Money}

There is a money-issuing authority in each country that issues the domestic currency. Money in this environment is perfectly divisible and storable - agents can carry any nonnegative quantity of money. We will denote the vector of currency holdings of an agent from

country $i$ as $M_{t}^{i}=\left[\begin{array}{llll}m_{\alpha, t}^{i} & m_{\beta, t}^{i} & m_{\gamma, t}^{i}\end{array}\right]^{\prime}$. Since agents can carry any non-negative quantity of money, we need to keep track of the distribution of money holdings in the economy. Let $F_{t}^{i}\left(M_{t}^{i}\right)$ be the CDF of money holdings by agents in country $i$ at time $t$. The total money supply of currency $c$ at time $t, \bar{m}_{c, t}$, is then:

$$
\sum_{i} n_{i} \int m_{c, t}^{i} d F_{t}^{i}\left(m_{c, t}^{i}\right)=\bar{m}_{c, t}
$$

Each period, the money supply grows at a rate $g_{c, t}$, which is deterministic. As such, $\bar{m}_{c, t+1}=\left(1+g_{c, t}\right) \bar{m}_{c, t}$. The money supply injections are transferred in a lump sum fashion to the agents in the economy during the centralized market subperiod.

\subsection{Timing}

The timing of activities during a period is as follows: At the beginning of each period, agents enter the decentralized market where they produce and consume differentiated goods. At the end of the decentralized market subperiod, the agents interact in a centralized market environment. In this subperiod, the agents decide how much of the homogenous good to produce and adjust their portfolio of currencies.

\section{Decision problems of agents}

We now describe the specific decision problems of the agents in the model. We begin by describing the decision problem of the agents in the centralized market, and then, we describe the decision problem in the decentralized market. 


\subsection{Decision problem of agents in centralized markets}

In the centralized market, agents decide on the quantity of the homogenous good to produce as well as the quantity of money balances to bring forward to the next period. Let's denote the nominal price of a homogenous good produced in country $i$ as $P^{i}$ units of currency $i$. Accordingly, the price of this good faced by an agent in country $j$ in terms of currency $j$ is $e_{j / i} P^{i}$, where $e_{j / i}$ is the exchange rate between the currency of country $j$ and the currency of country $i$ (quantity of currency $j$ needed to purchase 1 unit of currency i). Given that homogenous goods produced in all countries are identical and that there are no transportation costs, arbitrage in the goods market will necessitate that the law of one price holds so that $e_{j / i} P^{i}=P^{j}$.

Let $W^{i}\left(M_{t}^{i} ; I_{t}^{i}\right)$ denote the value function for an agent from country $i$ who enters the centralized market with currency holdings, $M_{t}^{i}$. $I_{t}^{i}$ refers to information known to the trader at time $t$ that will be relevant for the trader's decision. The information set consists of the distribution of money balances of agents in other countries, their respective rates of money growth and the invoicing pattern in next period's decentralized market. Based on the setup described above, we have the following:

$$
W^{i}\left(M_{t}^{i} ; I_{t}^{i}\right)=\max _{x^{i}, y^{i}, M_{t+1}^{i}} U\left(x^{i}\right)-y^{i}+\delta V^{i}\left(M_{t+1}^{i} ; I_{t+1}^{i}\right)
$$

subject to

$$
x^{i}+\phi_{t}^{i} \sum_{c} e_{i / c, t} m_{c, t+1}^{i} \leq y_{t}^{i}+\phi_{t}^{i} \sum_{c} e_{i / c, t} m_{c, t}^{i}+g_{i, t} \phi_{t}^{i} \bar{m}_{i, t} / n_{i}
$$

where the continuation value, $V^{i}(\cdot)$, is the value function associated with the decentralized market in the next period. The other variables used above are described as follows: $x^{i}$ and $y^{i}$ are the consumption and production of the homogenous good respectively, $\phi_{t}^{i}=1 / P_{t}^{i}$ is the inverse of the nominal price of a homogenous good produced in country $i$ at time $t$ and $g_{i, t}$ is the growth rate of money supply for country $i . g_{i, t} \phi_{t}^{i} \bar{m}_{i, t} / n_{i}$ represents the per-capita lump-sum transfer of newly-created money.

\subsection{Decision problem of agents in decentralized market}

We next describe the decision problem faced by the agents in the decentralized market. In a bilateral meeting where there is a single coincidence of wants, agents enter into a 
bargaining game to decide the quantity of goods and money exchanged. Let $q_{c}^{i, j}\left(M^{i}, M^{j}\right)$ be the amount of differentiated goods and $d_{c}^{i, j}\left(M^{i}, M^{j}\right)$ the amount of money exchanged when a buyer from country $i$ meets a seller from country $j$ and trade is denominated in currency $c$. At this point, we allow for these quantities to depend on the money balances of both the buyer and the seller. ${ }^{12}$ The price of the differentiated good in currency $c$ units is therefore $\frac{d_{c}^{i, j}}{q_{c}^{i, j}}$. The bargaining problem will take on the Nash form as follows:

$$
\begin{aligned}
& \max _{q_{c}^{i, j}, d_{c}^{i, j}}\left[u\left[q_{c}^{i, j}\left(M^{i}, M^{j}\right)\right]+W\left(M^{i}-I_{c} \cdot D^{i, j}\left(M^{i}, M^{j}\right) ; I_{t}^{i}\right)-W\left(M^{i} ; I_{t}^{i}\right)\right]^{\theta} \\
& {\left[-q_{c}^{i, j}\left(M^{i}, M^{j}\right)+W\left(M^{j}+I_{c} \cdot D^{i, j}\left(M^{i}, M^{j}\right) ; I_{t}^{i}\right)-W\left(M^{j} ; I_{t}^{i}\right)\right]^{1-\theta}}
\end{aligned}
$$

The notation $D^{i, j}\left(M^{i}, M^{j}\right)$ represents the vector of money transfers from buyer $i$ to seller $j$ in all the possible currencies: $D^{i, j}=\left[\begin{array}{lll}d_{\alpha}^{i, j} & d_{\beta}^{i, j} & d_{\gamma}^{i, j}\end{array}\right]^{\prime} \cdot I_{c}$ is a $3 \times 3$ matrix with ones on the diagonal elements representing the transaction currencies and zeros elsewhere. The product of $I_{c}$ and $D$ then captures the amount in the respective currencies that needs to be subtracted or added to the money balances of the buyer and the seller respectively. $\theta$ represents the bargaining power of the buyer. For the analysis that follows, we will assume that the buyer and the seller have equal bargaining power, so $\theta=0.5$.

The bargaining problem above is subject to a constraint that states that the amount of money transferred cannot be more than the amount of that particular currency that the buyer possesses. We will refer to this constraint as the "currency constraint". In the baseline model, only the currency of invoice is allowed to be used. So, the currency constraint is $d_{c}^{i, j} \leq m_{c}^{i}$ where $c$ is the currency of invoice and $d_{c^{\prime}}^{i, j}=0$ for all other currencies $c^{\prime}$. In the extension presented in Section 6, we relax this restriction and allow all currencies to be used.

\section{The baseline model}

In this section, we discuss the specific details of the baseline model. We begin by discussing the invoicing decisions made by agents.

\footnotetext{
${ }^{12} q$ and $d$ can also depend on time. Here, we have suppressed the time subscripts. Later on, we will be restricting ourselves to stationary equilibria where $q$ is constant.
} 


\subsection{Strategic decisions by agents}

During the centralized market subperiod, agents make strategic decisions regarding the invoicing of their trade should they meet a potential buyer in the next period. The agent's strategy will be a function that maps elements from the set of nationalities of agents to the set containing the three possible invoicing currencies. ${ }^{13}$ We will denote the strategy of an agent from country $i$ who decides to invoice her trade with an agent from country $j$ in currency $c$ with the notation $s_{c}^{j i}=1$. An agent's decision on the currency of invoice will be based on the denomination that gives her the largest surplus.

Here, we introduce a restriction in the strategy space of agents that we feel is empirically relevant. All domestic trade has to be conducted in domestic currency. While this restriction rules out the study of some interesting phenomena such as "dollarization", this is not the focus of this paper. This restriction basically guarantees a positive demand for balances in the domestic currency so that currencies do not go out of circulation. While we believe that the restriction is empirically plausible, it does have implications on the welfare computations which will be further discussed in Section 7 .

We now introduce some terminology that we will be utilizing in later sections of the paper: If a currency is used as a currency of invoice in international transactions, we will term that currency an "international currency". If the proportion of international transactions that are carried out in a particular equilibrium is higher than in another equilibrium, we will say that the currency is "more internationally used" in the equilibrium where the proportion of international transactions invoiced in it is higher.

Buyers faced with an invoicing decision by a potential seller decide whether to enter into the bargaining game or not. We denote a buyer from country $i$ 's decision to trade when faced with an agent from country $j$ who is denominating her trade in currency $c$ with $b_{c}^{i j}$. This variable is equal to one if the buyer agrees and zero otherwise.

\footnotetext{
${ }^{13}$ More generally, we can define the domain of the agents strategy set to be the money balances held by the buyer. As it turns out, the distribution of money balances within each country is degenerate and so we lose nothing by defining the domain just to be the set of nationalities.
} 


\subsection{Value function in the decentralized market}

Based on the setup above, we can write the value function for an agent from country $i$ as she enters the decentralized market as

$$
\begin{aligned}
V^{i}\left(M_{t}^{i} ; I_{t}^{i}\right)= & \sum_{j} \sum_{c} \mu_{i j} \sigma s_{c}^{i j} b_{c}^{i j} \int\left\{u\left(q_{c}^{i, j}\right)+W\left(M^{i}-I_{c} \cdot D^{i, j} ; I_{t}^{i}\right)\right\} d F_{t}^{j}\left(M_{t}^{j}\right) \\
& +\mu_{i j} \sigma s_{c}^{j i} b_{c}^{j i} \int\left\{-q_{c}^{j, i}+W\left(M^{i}+I_{c} \cdot D^{j, i} ; I_{t}^{i}\right)\right\} d F_{t}^{j}\left(M_{t}^{j}\right) \\
& +\left(1-\sum_{j} 2 \mu_{i j} \sigma\right) W\left(M_{t}^{i} ; I_{t}^{i}\right)
\end{aligned}
$$

where the dependence of $q_{c}^{i, j}$ and $d_{c}^{i, j}$ on $M^{i}$ and $M^{j}$ is suppressed.

In any given meeting where there is a single coincidence of wants, an agent can either be a buyer or a seller in the transaction. The first term in the expression above is the expected value of being a buyer for an agent from country $i$ when she meets an agent from country $j$. $\mu_{i j}$ is the probability of meeting that agent, $\sigma$ is the probability of the single coincidence of wants, $s_{c}^{i j}$ represents the invoicing strategy of the seller and $b_{c}^{i j}$ represents the strategy of the buyer. Since we allow for the quantities to depend on the money balances of the seller, we need to find the expected value of the seller's money balances. Hence, we integrate over the entire distribution of the seller's money holdings. The second term captures the expected value for the agent from country $i$ of being a seller, while the third term captures the value in the event where there is no single coincidence meeting or no meeting at all.

\subsection{Equilibrium}

We begin by stating the definition of an equilibrium for this economy.

An equilibrium in this economy is a set of strategies, $\left\{s_{c}^{i j}, b_{c}^{i j}\right\} \forall i, j, c$, prices $\left\{\phi_{t}^{i}, e_{c / c^{\prime}}\right\}$ $\forall i, c, c^{\prime}$, quantities in the centralized market $\left\{x_{t}^{i}, y_{t}^{i}, M_{t+1}^{i}\right\} \forall i, t$, quantities in the decen-

tralized market $\left\{q_{c, t}^{i, j}, d_{c, t}^{i, j}\right\} \forall i, j, c, t$, distribution of money holdings $F_{t}^{i}\left(M_{t}^{i}\right) \forall i, t$ and value functions $\left\{V_{t}^{i}, W_{t}^{i}\right\} \forall i, t$ such that

1. Strategies form a pure strategy Nash Equilibrium.

2. Value functions and quantities in the centralized market solve (2) and (4) taking prices and the distribution of money holdings as given. 
3. Agents solve the symmetric bargaining problem in the decentralized market as stated in (3) taking prices as given.

4. Market for money balances clears: $\sum_{i} n_{i} \int m_{c, t}^{i} d F_{t}^{i}\left(m_{c, t}^{i}\right)=\bar{m}_{c, t} \forall c, t$.

5. Market for homogenous goods clears: $\sum_{i} y_{i}=\sum_{i} x_{i} \forall i$.

For the purposes of this paper, we will be restricting ourselves to stationary equilibria, where the quantity of differentiated goods traded in the decentralized market is constant over time, $q_{c, t}^{i, j}=q_{c, t+1}^{i, j} \forall t$. To solve for the equilibria of this economy, we first derive some useful results in the centralized market problem. Following that, we solve for the quantities of goods and money exchanged in the bilateral meetings in the decentralized market.

\subsection{Centralized Market Problem}

In this subsection, we derive some useful properties associated with the centralized market. From equation (2) in the previous section, we can substitute for $y_{t}^{i}$ in the objective function from the budget constraint to get

$$
\begin{aligned}
W\left(M_{t}^{i} ; I_{t}^{i}\right)= & \phi_{t}^{i}\left(e_{i / \alpha, t} m_{\alpha, t}^{i}+e_{i / \beta, t} m_{\beta, t}^{i}+e_{i / \gamma, t} m_{\gamma, t}^{i}+g_{i, t} \bar{m}_{i, t} / n_{i}\right)+\max _{x_{t}^{i}}\left[U\left(x^{i}\right)-x_{t}^{i}\right] \\
& +\max _{M_{t+1}^{i}}\left[-\phi_{t}^{i}\left(e_{i / \alpha, t} m_{\alpha, t+1}^{i}+e_{i / \beta, t} m_{\beta, t+1}^{i}+e_{i / \gamma, t} m_{\gamma, t+1}^{i}\right)\right] \\
& +\max _{M_{t+1}^{i}}\left[\delta V\left(M_{t+1}^{i} ; I_{t+1}^{i}\right)\right]
\end{aligned}
$$

From equation (5), we see that the agent's choice of next period's money holdings is independent of the respective values in the current period. This feature of the model is a result of the linear functional form assumption for the disutility associated with the production of the homogenous good, which removes any wealth effects from the agent's choice. The value function above also has another useful property in that it is linear with respect to current money balances. We will exploit this feature in the next subsection. ${ }^{14}$

In any equilibrium, the following two first order conditions must hold for all $i$ and $c$ :

$$
\begin{aligned}
& U^{\prime}\left(x_{t}^{i}\right)=1 \\
& \phi_{t}^{i} e_{i / c, t} \geq \delta V_{m_{c}^{i}}\left(M_{t+1}^{i} ; I_{t+1}^{i}\right)=\text { if } m_{c}^{i}>0
\end{aligned}
$$

\footnotetext{
${ }^{14}$ The restriction that $0<y$ will not be imposed now, but will be verified during the quantitative analysis.
} 
where $V_{m_{c}^{i}}$ denotes the partial derivative of $V$ with respect to the balances held in currency c. Equations (6) and (7) have the standard interpretation of equating marginal benefits to marginal costs. In equation (6), the marginal utility of consuming an additional unit of the homogenous good is equated to the marginal cost of production, which in this case is 1. Similarly, the left-hand side of equation (7) represents the marginal cost associated with holding an extra unit of currency in terms of units of the homogenous good. The righthand side, meanwhile, represents the marginal benefit associated with holding an extra unit of the currency. The benefit comes from the ability to purchase extra units of both the differentiated good and the homogenous good in the next period.

\subsection{Bargaining Solutions}

In the last subsection, we noted that the value function in the centralized market has a useful property in that it is linear with respect to current money balances. This property allows for an easier restatement of the bargaining problem in (3). The bargaining problem between buyer $i$ and seller $j$ trading in currency $c$ can be restated as follows:

$$
\max _{q_{c}^{i, j}, d_{c}^{i, j}}\left[u\left(q_{c}^{i, j}\right)-\phi^{i} e_{i / c} d_{c}^{i, j}\right]\left[-q_{c}^{i, j}+\phi^{j} e_{j / c} d_{c}^{i, j}\right]
$$

subject to

$$
d_{c}^{i, j} \leq m_{c}^{i}
$$

where the notation indicating the dependence of $q$ and $d$ on the money balances of the buyer and the seller have been suppressed.

The equilibrium quantity of goods and currency exchanged will depend on whether the currency constraint binds or not. If the currency constraint does not bind, then it can be shown that the quantity of goods exchanged is given by the following first-order condition:

$$
u^{\prime}\left(q_{c}^{i, j}\right)\left(\frac{\phi^{j} e_{j / c}}{\phi^{i} e_{i / c}}\right)=1
$$

Since the law of one price holds for homogenous goods, we have that $\left(\frac{\phi^{j} e_{j / c}}{\phi^{i} e_{i / c}}\right)=1$. Therefore, if the currency constraint does not bind, we have $q_{c}^{i, j}=q^{*}$ where $q^{*}$ is the efficient quantity of goods exchanged and is implicitly defined by $u^{\prime}\left(q^{*}\right)=c^{\prime}\left(q^{*}\right)=1$. The currency exchanged, $m_{c}^{i *}$, is given by

$$
\phi^{i} e_{i / c} m_{c}^{i *}=\frac{1}{2} q^{*}+\frac{1}{2} u\left(q^{*}\right)
$$


If the currency constraint does bind, we have that $d_{c}^{i, j}=m_{c}^{i}$ and the quantity exchanged is given by

$$
\phi^{i} e_{i / c} m_{c}^{i}=\frac{u^{\prime}\left(q_{c}^{i, j}\right) q_{c}^{i, j}+u\left(q_{c}^{i, j}\right)}{u^{\prime}\left(q_{c}^{i, j}\right)+1} \equiv z\left(q_{c}^{i, j}\right)
$$

In both the cases when the constraint binds and when the constraint does not bind, neither the currency nor the quantity transferred depend on the money balances of the seller, so we can drop the seller superscripts from $d$ and $q$. Furthermore, the quantity transferred does not depend on the buyer's holdings of other currencies apart from the transactions currency. These results follow directly from the specification of the constraint in the bargaining problem.

\subsection{Optimal quantity of money balances and differentiated goods ex- changed}

In the previous subsection, we saw that the amount of goods and currency that are exchanged in the decentralized markets depend on whether the currency constraint is binding or not. In this subsection, we combine the results from the bargaining problem and the centralized market problem and consider the problem of the optimal quantity of money balances to be brought forward to the next period.

Following Lemma 1 in the Appendix, we can rewrite the first-order condition for both the case where the currency constraint binds $\left(m_{c, t+1}^{i}<m_{c, t+1}^{i *}\right)$ and where it does not bind $\left(m_{c, t+1}^{i} \geq m_{c, t+1}^{i *}\right)$ as follows:

$$
\begin{aligned}
\phi_{t}^{i} e_{i / c, t} \geq \delta \mu_{c}^{i} \sigma u^{\prime}\left(q_{t+1}^{i}\right) q_{c, t+1}^{i \prime}+\left(1-\mu_{c}^{i} \sigma\right) \phi_{t+1}^{i} e_{i / c, t+1} & \text { for } m_{c, t+1}^{i}<m_{c, t+1}^{i *} \\
\phi_{t}^{i} e_{i / c, t}=\delta \phi_{t+1}^{i} e_{i / c, t+1} & \text { for } m_{c, t+1}^{i} \geq m_{c, t+1}^{i *}
\end{aligned}
$$

There are two changes in the notation used above. First, the superscript in the quantity of differentiated goods traded, $q$, now only shows the nationality of the buyer since we saw that the money balances of the seller do not affect the quantities traded. Second, the "meeting" parameter, $\mu_{c}^{i}$, captures all the bilateral meetings where the agent from country $i$ is the buyer and trade is conducted in currency $c$, i.e. $\mu_{c}^{i}=\sum_{j} \mu_{i j} s_{c}^{i j} b_{c}^{i j}$. For example, if agents in country $A$ and $B$ are denominating their trade with country $C$ in currency $\alpha$, then the relevant meeting parameter in the equation above for an agent from country $C$ will be $\mu_{\alpha}^{C}=\mu_{C A}+\mu_{C B}$. 
Lemma 2 in the Appendix shows that in any monetary equilibrium, the currency constraint in the bargaining problem will be binding. As such, the relevant first-order condition in any monetary equilibrium is given by equation (11). It should be noted, however, that we are not guaranteed a unique solution (a unique value for $q$ ). Uniqueness is guaranteed if $V$ is concave, i.e. if $V_{m_{c}^{i} m_{c}^{i}} \leq 0$. In the section on quantitative analysis, we will verify the concavity of $V$ empirically. At this juncture, however, we will make sufficient assumptions on the utility function $u(\cdot)$ such that $V_{m_{c}^{i} m_{c}^{i}} \leq 0 .{ }^{15}$ With a unique solution (a unique value for $q$ ), we then have a degenerate distribution of money holdings for all periods. All agents in a particular country demand the same quantity of real money balances in accordance with equation (10) for a given value of $q$.

We now determine the equilibrium quantity of differentiated goods exchanged. From equation (10), we get $q_{c, t+1}^{i \prime}=\phi_{t+1}^{i} e_{i / c, t+1} z^{\prime}(q)$. Substituting this into equation (11) and dividing both sides by $\phi_{t}^{i} e_{i / c, t}$, we get $^{16}$

$$
1=\delta\left[\mu_{c}^{i} \sigma \frac{u^{\prime}\left(q_{c}^{i}\right)}{z^{\prime}\left(q_{c}^{i}\right)}-\mu_{c}^{i} \sigma+1\right]\left(\frac{1}{1+g_{c, t}}\right)
$$

The constant value of $q$ that solves the equation above gives us the stationary equilibrium quantity of differentiated goods traded in a bilateral match where the buyer is from country $i$ and the trade is carried out in currency $c, q_{c}^{i}$. Plugging this value of $q$ into equation (10) gives us the real balances in currency $c$ demanded by an agent from country $i$.

\subsection{Equilibrium invoicing strategies}

In any equilibrium, we will also need to verify that the agent's decision to invoice their trade in a particular currency is optimal given the equilibrium money balances and strategies of buyers from different countries. An agent from country $i$ 's surplus from the decision to invoice her trade in currency $c$ with a buyer from country $j$ is $-q_{c}^{j}+W\left(M^{i}+I_{c} \cdot D^{j}\right)$. The seller will choose to denominate her trade in currency $c$ if and only if

$$
-q_{c}^{j}+W\left(M^{i}+I_{c} \cdot D^{j}\right) \geq-q_{c^{\prime}}^{j}+W\left(M^{i}+I_{c^{\prime}} \cdot D^{j}\right)
$$

\footnotetext{
${ }^{15}$ A sufficient assumption in this case would be to assume that $u^{\prime}$ is log concave (see Lagos-Wright (2005)). This assumption is merely sufficient and not necessary. In most practical applications, such as the one carried out in this paper, uniqueness is still obtained even though $u^{\prime}$ is not log-concave.

${ }^{16}$ We have utilized the result derived in subsection 4.8 which shows that $\frac{\phi_{t+1}^{c}}{\phi_{t}^{c}}=\frac{1}{1+g_{c, t}}$.
} 
for all alternative currencies, $c^{\prime}$, given the strategies of the other agents.

We now present some comparative statics results regarding the surplus of the seller which will be useful when we analyze the welfare implications later on.

Proposition 1 Let the seller's surplus of invoicing in currency $c$ be denoted as $S^{S} \equiv$ $-q_{c}^{j}+W\left(M^{i}+I_{c} \cdot D^{j}\right)$. We then have

(i) $\left.\frac{\partial S^{S}}{\partial q}\right|_{q<q^{*}}>0$

(ii) $\frac{\partial q_{c}^{i}}{\partial \mu_{c}^{i}}>0$

(iii) $\frac{\partial q_{c}^{i}}{\partial g_{c}}<0$

The results in Proposition 1 highlight the network externalities present in the model. This can be seen by considering the problem of an agent from $A$ who is deciding how to invoice his trade with agents from $B$. Assume initially that agents from country $C$ are invoicing their trade with agents from $B$ in $\alpha$ and that the best response for agents in country $A$ is to invoice in currency $\beta$ with agents from country $B$. Now suppose that agents from country $C$ decide to invoice in currency $\beta$. From parts (i) and (ii) of Proposition 1, this increases the surplus to agents from country $A$, i.e. $S_{\beta}^{S}$, as $\mu_{\beta}^{B}$ will now be higher. If the initial best response of country $A$ 's agents was to invoice in some other currency $c^{\prime}$, the move by country $C$ agents to invoice in $\beta$ weakly reduces their surplus (strictly reduces is the best response was originally currency $\alpha$ ).

Potential buyers in this model will always find it optimal to accept an offer to trade in a particular currency if she has balances in that currency. The proof for this is trivial since buyers are always guaranteed a positive surplus when entering the bargaining game and there is only one meeting in each day subperiod. If the buyer does not have balances in the invoicing currency, she is indifferent as she gets a net surplus of zero in either case. We resolve this indifference by assuming that the buyer decides not to accept the offer to trade.

\subsection{Prices}

The inverse of the price for the homogenous good $\phi_{t}^{i}=1 / P_{t}^{i}$ can be found through the market clearing condition for money balances: 


$$
\begin{aligned}
\phi_{t}^{i} e_{i / c, t} \sum_{j} n_{j} m_{i}^{j} & =\phi_{t}^{i} e_{i / c, t} \bar{m}_{c, t} \\
\Rightarrow \phi_{t}^{c} & =\frac{\sum_{j} n_{j} z\left(q_{c}^{j}\right)}{\bar{m}_{c, t}}
\end{aligned}
$$

where we use $\phi_{t}^{c}$ to denote the inverse price level for the country that issues currency $c$. Note that the model features neutrality in the sense that changes in the money supply only affect the general price level since the quantity of real balances is stationary. The inflation

rate in this economy is given by $\frac{P_{t+1}^{c}}{P_{t}^{c}}=1+g_{c, t+1}$. The model, however, is not superneutral. Changes in the inflation rate will affect the equilibrium quantity of goods exchanged in the decentralized markets, $q_{c}^{i}$, through equation (13). The following proposition relates the general price level to the international use of the currency.

Proposition 2 As we move from an equilibrium where currency $c$ is more internationally used to one where it is less internationally used, the price level in the issuing country increases.

This result is similar to the result found in Wright and Trejos (2001) where they show that a currency's purchasing power at home rises when a currency is used internationally. At a qualitative level, this provides some theoretical explanation as to why the price level for the US is a consistent outlier in cross-country income-price regressions.

\section{Welfare benefits of an international currency}

Since the emergence of the euro as a viable alternative international currency, there has been great interest in the consequences of a transfer of the dollar's premier international role to the euro. Papers by Chinn and Frankel (2005) and Eichengreen (2005) discuss possible scenarios related to a loss in the key international role of the dollar. The model developed in the previous sections provides a framework in which we can discuss the welfare implications of any such transitions.

To analyze the model's welfare implications associated with a wider international use of a currency, we study differences in welfare across three specific equilibria of interest, which we shall label as Equilibrium I, II and III. These three equilibria capture several 


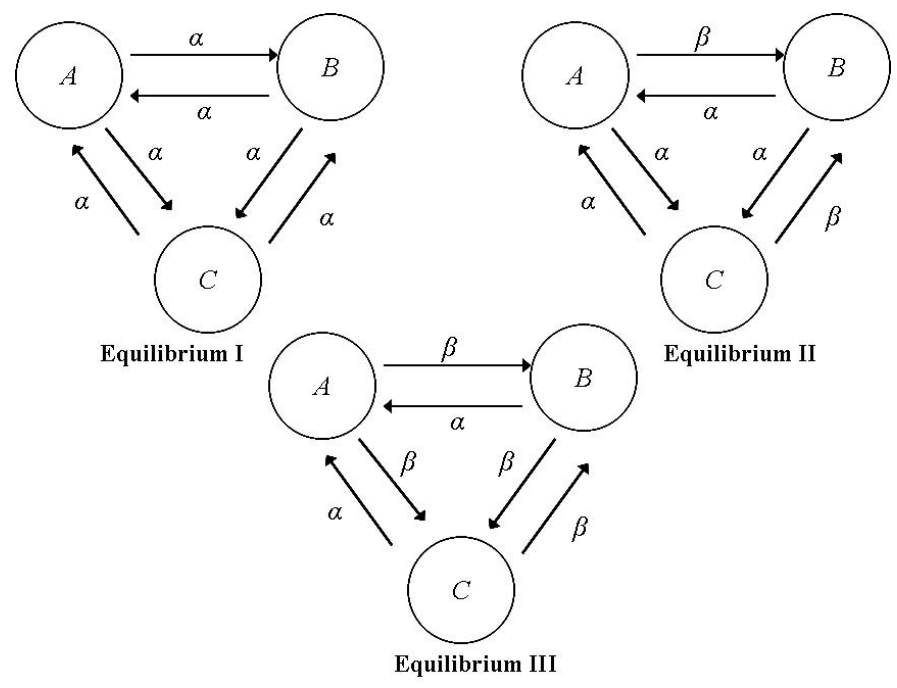

Figure 1: Pattern of trade invoicing in the equilibria analyzed (arrow from $i$ to $j$ indicates $i$ exporting to $j$ )

possibilities when there are two prominent currencies in the world, such as is the case currently with the euro and the US dollar. The equilibria that we study are defined by the pattern of trade invoicing, which is shown in Figure 1. Equilibrium I is one where currency $\alpha$ functions as the only international currency. All international trade in this equilibrium is conducted using currency $\alpha$. Equilibrium II is one where all invoicing vis-a-vis country $B$ is carried out in currency $\beta$. Trade with country $C$, however, is still carried out in currency $\alpha$. Equilibrium III is one where trade with country $C$ is now also carried out in currency $\beta$. Thus, the international use of currency $\alpha$ diminishes as we move from Equilibrium I to Equilibrium III. These are, of course, not all the possible equilibria in this model. In general, we could have all permutations of invoicing between countries. For any given set of meeting parameters, an equilibrium is admissible if the invoicing patterns are optimal for all sellers as determined by equation (14). In the calibration exercise carried out in this paper, Equilibriums I, II and III are admissible and are the most interesting to analyze when there are two prominent currencies in the world.

The steady state value functions across the three equilibria differ not only in their equilibrium quantities, but also in their form. We will use the value function of agents in Country $B$ as an illustration of the main forces at work as we move across equilibria. 
The effects on agents from other countries can be assessed in an analogous manner. For Equilibrium I, we can write the steady-state value function for Country $B$ as ${ }^{17}$

$$
\begin{aligned}
(1-\delta) V_{(I)}^{B}= & U\left(x^{B *}\right)-x^{B *}+\mu_{B B} \sigma\left[u\left(q_{\beta(I)}^{B}\right)-q_{\beta(I)}^{B}\right] \\
& +\mu_{B A} \sigma\left[u\left(q_{\alpha(I)}^{B}\right)-q_{\alpha(I)}^{A}-\phi_{(I)}^{A}\left(m_{\alpha(I)}^{B}-m_{\alpha(I)}^{A}\right)\right] \\
& +\mu_{B C} \sigma\left[u\left(q_{\alpha(I)}^{B}\right)-q_{\alpha(I)}^{C}-\phi_{(I)}^{A}\left(m_{\alpha(I)}^{B}-m_{\alpha(I)}^{C}\right)\right] \\
& -g_{\alpha} \phi_{(I)}^{A} m_{\alpha(I)}^{B}
\end{aligned}
$$

The first two terms in the value function represent the utility derived from consumption of the homogenous good. $x^{B *}$ is the optimal amount of the homogenous good that is consumed. The next three terms represent the utility derived from transactions in the decentralized market. The last term in equation (16) captures the seignorage transfer that has to be made to country $A$ due to the demand for balances in currency $\alpha$ by agents in country $B$.

In the case of equilibrium II, the steady-state value function takes on the following form:

$$
\begin{aligned}
(1-\delta) V_{(I I)}^{B}= & U\left(x^{B *}\right)-x^{B *}+\mu_{B B} \sigma\left[u\left(q_{\beta(I I)}^{B}\right)-q_{\beta(I I)}^{B}\right] \\
& +\mu_{B A} \sigma\left[u\left(q_{\beta(I I)}^{B}\right)-q_{\alpha(I I)}^{A}-\phi_{(I I)}^{B} m_{\beta(I I)}^{B}+\phi_{(I I)}^{A} m_{\alpha(I I)}^{A}\right] \\
& +\mu_{B C} \sigma\left[u\left(q_{\beta(I I)}^{B}\right)-q_{\alpha(I I)}^{C}-\phi_{(I I)}^{B} m_{\beta(I I)}^{B}+\phi_{(I I)}^{A} m_{\alpha(I I)}^{C}\right]
\end{aligned}
$$

When we move to Equilibrium II, we note that consumption of the homogenous good in the centralized market remains the same as in Equilibrium I. The value obtained from domestic transactions, however, has changed. In Equilibrium II, agents from country $B$ can now use currency $\beta$ for all their transactions, not just domestic transactions as in Equilibrium I. As such, $\mu_{\beta(I I)}^{B}>\mu_{\beta(I)}^{B}$. From Proposition 1, holding other parameters constant, we have that $q_{\beta(I I)}^{B}>q_{\beta(I)}^{B}$. Since in any monetary equilibrium, $q<q^{*}$, we have that $u^{\prime}<1$. Therefore, comparing Equilibriums I and II, we see that the international use of currency $\beta$ has increased the net benefit that agents from country $B$ obtain from domestic transactions.

The value obtained from transactions with country $A$ and $C$ also change. The change comes from the fraction of transactions where agents from country $B$ are buyers. In these

\footnotetext{
${ }^{17}$ The roman numeral subscripts refer to the respective equilibrium.
} 
transactions, the relevant comparison is between the buyer's net surplus in Equilibrium I and Equilibrium II, i.e. between $\left[u\left(q_{\beta(I I)}^{B}\right)-\phi_{(I I)}^{B} m_{\beta(I I)}^{B}\right]$ and $\left[u\left(q_{\alpha(I)}^{B}\right)-\phi_{(I)}^{A} m_{\alpha(I)}^{B}\right]$. We know that $\mu_{\beta(I I)}^{B}>\mu_{\alpha(I)}^{B}$ and so, holding everything else constant, we have that $q_{\beta(I I)}^{B}>$ $q_{\alpha(I)}^{B}$. We can show from equation (13) that, as long as $\left(1+g_{c}\right)>\delta,{ }^{18}$ the buyer's surplus is increasing in $q .{ }^{19}$ Therefore, if inflation rates are the same across both currencies $\alpha$ and $\beta$, the surplus that agents from country $B$ get from purchases from agents from country $A$ and $C$ increases.

As shown above, the international use of currency $\beta$ has increased the value associated with both domestic and international transactions for agents from country $B$. The intuition for this result is as follows. In the centralized market, agents have to decide on how to allocate resources between present consumption and money balances. If every transaction that the agent can expect to conduct in the next period is carried out in the same currency, then the decision is made based on the rate of inflation and the share of the surplus the buyer expects to get in each transaction. The higher the rate of inflation, the lower the money balances held by the agent as she would divert more resources towards present consumption. The same effect would occur if she got a lower share of the surplus from transactions in the decentralized market. If instead, different transactions that the agent expects to carry out next period are invoiced in different currencies, the agent has now another dimension to her choice. She now has to allocate resources between present consumption, balances in currency $\alpha$, say, and balances in currency $\beta$. If the inflation rates and the share of the surplus are the same for both currencies, the agent will hold balances in each currency as a function of the proportion of transactions she expects to carry out in that currency next period. Since she now has to decide between multiple currencies, the fraction of her resources that she invests in balances in any one currency will be less than the fraction of resources she would have invested had all her next-period trade been conducted in one currency. The surplus in any trade, however, is increasing in the amount of real balances brought into the trade by the buyer. ${ }^{20}$ Therefore, compared to an equilibrium where the agent has to invest in multiple currencies, the total surplus for each transaction in an equilibrium where the agent's currency is accepted everywhere is higher. In Equilibrium II, currency $\beta$ is internationally used so agents from country $B$ do not have to hold balances of

\footnotetext{
${ }^{18}$ That is, as long as we are away from the Friedman Rule.

${ }^{19}$ See equation (23) in the proof for Proposition 1 in the Appendix.

${ }^{20}$ See proof for Proposition 1.
} 
currency $\alpha$ anymore. As such, the surplus they obtain from all purchases that they make increase. It is this effect that we term the terms-of-trade effect.

The higher international use of currency $\beta$ also yields another benefit for country $B$ agents. Since all the agents now invoice their trade with $B$ in currency $\beta$, agents from country $B$ no longer hold any foreign currency balances. Therefore, there is no seignorage transfer to country $A$ as in Equilibrium I.

For equilibrium III, the steady-state value function takes on the following form

$$
\begin{aligned}
(1-\delta) V_{(I I I)}^{B}= & U\left(x^{B *}\right)-x^{B *}+\mu_{B B} \sigma\left[u\left(q_{\beta(I I I)}^{B}\right)-q_{\beta(I I I)}^{B}\right] \\
& +\mu_{B A} \sigma\left[u\left(q_{\beta(I I I)}^{B}\right)-q_{\alpha(I I I)}^{A}-\phi_{(I I I)}^{B} m_{\beta(I I I)}^{B}+\phi_{(I I I)}^{A} m_{\alpha(I I I)}^{A}\right] \\
& +\mu_{B C} \sigma\left[u\left(q_{\beta(I I I)}^{B}\right)-q_{\beta(I I I)}^{C}-\phi_{(I I I)}^{B} m_{\beta(I I I)}^{B}+\phi_{(I I I)}^{B} m_{\beta(I I I)}^{C}\right] \\
& +g_{\beta}\left[\phi_{(I I I)}^{B} \frac{\bar{m}_{\beta}}{n_{B}}-\phi_{(I I I)}^{B} m_{\beta(I I I)}^{B}\right]
\end{aligned}
$$

The net benefit obtained from the centralized market once again does not change relative to Equilibrium I. The net surplus associated with domestic transactions and transactions with agents from country $A$ will also be the same as in Equilibrium II. Transactions with agents from country $C$, where agents from country $B$ are the sellers, are now invoiced in currency $\beta$. However, if the inflation rate of currency $\beta$ is the same as that of currency $\alpha$, the surplus obtained from sales to agents from country $C$ will be the same as in the other two equilibria. This is so because, if $g_{\alpha}=g_{\beta}$, we have that $q_{\beta(I I I)}^{C}=q_{\alpha(I)}^{C}$ since $\mu_{\beta(I I I)}^{C}=\mu_{\alpha(I)}^{C}$. Agents from country $C$, however, now demand balances in currency $\beta$. Therefore, agents from country $B$ now receive seignorage revenues each period, as captured by the last term in equation (18). $\phi^{B} \frac{\bar{m}_{\beta}}{n_{B}}$ represents the per-capita quantity of real money supply, which will be larger than the per capita real domestic demand, $\phi^{B} m_{\beta}^{B}$. Note that the benefit from seignorage increases with the rate of inflation, $g_{\beta}$.

\subsection{Quantitative estimates for the baseline model}

We now proceed to present quantitative estimates regarding the welfare impact as we move across equilibria. To map the model to the data, we first need to do two things. Firstly, we need to determine the countries or regions of interest that will map into countries $A, B$, and $C$ in our model. Secondly, we need to find a counterpart in the data for the meeting 
parameters in the model, $\mu$. A suitable counterpart for countries $A, B$ and $C$ are the US, the Euro area and a composite for the "rest of the world", $R O W$. Although these groupings are not "countries" per se, we will continue to refer to them as such to ease the presentation. The $R O W$ composite will be an aggregate of all the remaining countries in the world (other than the US and the Euro area), with the exception of the UK and Japan. These two countries are excluded as we do not want to consider cases where the currency of "Country $C$ " can be used as an international currency. What we have in mind when we think of $R O W$ is primarily developing countries who do not have strong or convertible currencies of their own. ${ }^{21}$

We next turn our attention to quantifying the meeting parameters. The meeting parameters come in two types: domestic meetings and international meetings. Let $s_{i}$ be country $i$ 's share of world output and $\psi_{i j}$ be the share of country $i$ 's trade that is with country $j$. The meeting parameters for country $i$ are then calibrated in the following way: $\mu_{i i}=s_{i}$ and $\mu_{i j}=\psi_{i j} s_{j}$. As a country's relative output increases, it follows naturally that the measure of domestic transactions increase as well. International meetings, on the other hand, are governed by two variables: the share of trade conducted with that country and that country's relative size. The measure of meetings between two countries can therefore increase if either the share of trade between the two countries increase or if the trading partner's relative size increases. It can be readily verified that, under this parametrization, the sum of all meeting parameters for a given country will be less than one. Data for relative output shares were obtained from the World Development Indicators published by the World Bank while bilateral trade data are from the IMF's Direction of Trade Statistics. The values used are as at the end of 2002 .

The estimation of the meeting parameters, however, are subject to "adding-up" constraints that state that the total measure of meetings that agents from country $i$ have with agents from country $j$ has to be the same as the total measure of meetings that agents from country $j$ have with country $i^{22}$ Due to these constraints, of the six international meeting parameters, only three are separately identified. We use the parametrization described above to compute the two international meeting parameters for the US and the parameter

\footnotetext{
${ }^{21}$ What this implies in terms of the model is that in checking the optimal invoicing decision based on equation (14), we do not allow for the currency of country $C$ to be used for international transactions.

${ }^{22}$ See footnote 10 .
} 
Table 1

\begin{tabular}{ll} 
Calibrated values for model parameters \\
\hline \hline$\mu_{A A}$ & .3051 \\
$\mu_{A B}$ & .0315 \\
$\mu_{A C}$ & .2204 \\
$\mu_{B A}$ & .0297 \\
$\mu_{B B}$ & .1918 \\
$\mu_{B C}$ & .2591 \\
$\mu_{C A}$ & .0145 \\
$\mu_{C B}$ & .0116 \\
$\mu_{C C}$ & .3133 \\
$n_{A}$ & .0476 \\
$n_{B}$ & .0505 \\
$n_{C}$ & .9019 \\
\hline
\end{tabular}

for the euro area's meetings with the $R O W$ composite. The rest of the meeting parameters are then estimated from the constraints where we use the share of world population as reported by the International Programs Center of the U.S. Census Bureau for the respective values of $n_{i}{ }^{23}$. The resulting values for the meeting parameters are shown in Table 1.

We calibrate the model to fit quarterly data. As a check on robustness, we also fit the model to annual data. The results for both calibrations are similar. ${ }^{24}$ We follow Lagos and Wright and use the following two functional forms for the utility functions: $u(q)=\frac{q^{1-\eta}}{1-\eta}$ and $U(x)=B \ln x$. We calibrate the values of $\eta$ and $B$ to minimize the distance between the model-generated money demand function and the quarterly data for the US for the period 1959-2002. ${ }^{25}$ We use the seasonally-adjusted M1 stock, the 3-month treasury bill rate and quarterly nominal GDP data from the FRED database maintained by the St. Louis Federal Reserve. The values obtained for $(\eta, B)$ were $(0.7,0.8401)$. The earlier assumption of a linear cost function for production in the decentralized market together with the assumption of symmetric bargaining $(\theta=0.5)$ continue to be used here.

Other parameters that we need to obtain values for are $\delta, \sigma$ and $g_{c}$. As a starting

\footnotetext{
${ }^{23}$ The values are scaled up so that $\sum n_{i}=1$.

${ }^{24}$ The results for the annual model are presented in the Appendix.

${ }^{25}$ The lsqnonlin function in MATLAB was used.
} 
Table 2

Welfare Changes in Consumption Equivalent Terms Relative to Equilibrium I (\%)

\begin{tabular}{ccccccc}
\hline \hline & \multicolumn{2}{c}{$g_{\alpha}=g_{\beta}=.03$} & \multicolumn{2}{c}{$g_{\alpha}=.045 ; g_{\beta}=.062$} & \multicolumn{2}{c}{$g_{\alpha}=.03 ; g_{\beta}=.02$} \\
& \multicolumn{2}{c}{$g_{\gamma}=.03$} & \multicolumn{2}{c}{$g_{\gamma}=.10$} & \multicolumn{2}{c}{$g_{\gamma}=.05$} \\
\cline { 2 - 7 } & Eqm II & Eqm III & Eqm II & Eqm III & Eqm II & Eqm III \\
\hline $1-\Delta_{U S}$ & -0.33 & -0.98 & -0.46 & -1.24 & -0.32 & -0.95 \\
$1-\Delta_{E U R}$ & 1.17 & 1.78 & 1.37 & 2.12 & 1.16 & 1.68 \\
$1-\Delta_{R O W}$ & 0 & 0 & 0.01 & -0.01 & 0.02 & 0.04 \\
\hline
\end{tabular}

point, we assume symmetric values for all countries. We take $\delta$ to be equal to 0.9902 for all countries, which translates to an annualized real interest rate of $4 \%$. For $\sigma$, we use the value $0.125 .^{26}$ The value associated with $g_{c}$ corresponds to the steady-state inflation rate in the model. We initially use a value of $3 \%$ per year as a base case for all countries. We alter this in different scenarios later.

We study the welfare effects of moving across equilibria in a manner similar to Lucas (1987) by asking how much consumption agents demand (or are willing to give up) as compensation to move to another equilibrium. Specifically, we add a common factor, $\Delta$, to the consumption of the differentiated good in the decentralized market and to the consumption of the homogenous good in the centralized market. The amount $1-\Delta$ then gives us the percentage gain (or loss if $1-\Delta<0$ ) of consumption faced by the agent each period.

The equilibria are computed in the following manner: First, for the given calibration of parameters, we verify that the proposed invoicing pattern is optimal for the sellers using equation (14). If the condition is not satisfied, then the equilibrium is not admissible under the current calibration of the parameters. As mentioned earlier, Equilibriums I, II and III are all admissible. For any set of invoicing patters, we then use equations (13) and (10) to determine the optimal quantity of differentiated goods and real money balances demanded respectively. The rest of the equilibrium quantities then follow.

\footnotetext{
${ }^{26} \mathrm{~A}$ value of $\sigma=0.5$ maximizes the measure of meetings in the decentralized market where trade is carried out. We assume the maximum value for $\sigma$ in the annual model shown in the appendix. As we are using a quarterly model here, the probability of a single coincidence will be less than the annual model and so we scale down $\sigma$ accordingly.
} 
The results of the base case (3\% inflation for all currencies) are shown in the second and third columns of Table 2. The benefit of a higher surplus for the US from imports from the Euro area when moving from Equilibrium I to Equilibrium II is outweighed by the loss of seignorage revenues resulting in a net loss of $0.33 \%$ of consumption for the US. The $R O W$, who do not get any seignorage revenues, should experience an increase in welfare from a higher surplus from sales to the Euro area in Equilibrium II. However, the increase is close to zero due to the small share of $R O W$ trade with the Euro area. As we move to Equilibrium III, the welfare loss to the US increases, and the gain to the Euro area also increases as the the $R O W$ now does not hold any dollar balances and instead holds euros. We can thus back out the implied welfare benefit that is solely due to seignorage revenues vis-a-vis the rest of the world as $0.65 \%$ of consumption for the US and $0.61 \%$ for the Euro area.

For the Euro area, the welfare benefit of moving from an equilibrium where the euro is not used for any international transaction to one where it is used for the majority of transactions is roughly $1.8 \%$ of consumption. Note that the bulk of the benefit for the euro area was obtained from the move to Equilibrium II. The remaining benefit obtained from moving to Equilibrium III is just the net seignorage revenue. The $R O W$, meanwhile, is completely indifferent to whether it is the US dollar or the euro that is the international currency.

The next few columns of Table 2 show results under different inflation scenarios. Columns 4 and 5 show the welfare changes for the case where the inflation rates of the US and the Euro area were set at their historical averages over the period 1960-2000. Since there is no external demand for the currency of $R O W$, their inflation rate will have no relative welfare effects so we set $g_{\gamma}$ as $10 \%$. The welfare loss for the US in this scenario is higher than in the base case as the loss of seignorage revenues is higher due to higher inflation rates. Likewise, the benefit for the Euro area is higher due to higher inflation rates. The interesting result here is that when inflation rates differ across countries, the $R O W$ is not indifferent as to which currency circulates as the dominant international currency. The welfare benefit is the highest if the currency with the lowest inflation rate is used as the international currency.

The last case that we look at (columns 6 and 7) uses more forward-looking scenarios for inflation. For the Euro area, we assume that the ECB successfully achieves its inflation 
target of $2 \%$. For the US, we assume that the inflation rate will be lower than their historical average. We use a figure of $3 \%$ which was the average inflation in the 1990s. ${ }^{27}$ The results are in line with what we would expect. The $R O W$ benefit from moving to a currency with a lower inflation rate while the lower inflation rate also means a lower gain to the Euro area (as compared to the base scenario) due to lower seignorage revenues.

\section{Extension of the baseline model}

We now turn to the model where the buyer can use all currencies in her inventory during a transaction. Once we allow all currencies to be used, the individual identity of each currency will not matter anymore. In practice, however, individual identities of currencies do matter to the extent that it is costly to switch from one currency to another. We model this distinction by introducing transaction costs for the use of a currency different from that of the invoice currency. We maintain the restriction that only the domestic currency can be used to carry out domestic transactions.

The bargaining problem set out in equation (3) now takes on the following form:

$$
\begin{aligned}
\max _{q_{c}^{i, j}, d_{\alpha}^{i}, d_{\beta}^{i}, d_{\gamma}^{i}} & {\left[u\left(q_{c}^{i, j}\right)-\phi^{i}\left(e_{i / \alpha} d_{\alpha}^{i}+e_{i / \beta} d_{\beta}^{i}+e_{i / \gamma} d_{\gamma}^{i}\right)-\tau_{\alpha, c} \phi^{\alpha} d_{\alpha}^{i}-\tau_{\beta, c} \phi^{\beta} d_{\beta}^{i}-\tau_{\gamma, c} \phi^{\gamma} d_{\gamma}^{i}\right] } \\
& {\left[-q_{c}^{i, j}+\phi^{j}\left(e_{j / \alpha} d_{\alpha}^{i}+e_{j / \beta} d_{\beta}^{i}+e_{j / \gamma} d_{\gamma}^{i}\right)\right] }
\end{aligned}
$$

subject to

$$
d_{c^{\prime}}^{i} \leq m_{c^{\prime}}^{i} \quad \text { for } c^{\prime} \varepsilon\{\alpha, \beta, \gamma\}
$$

where the notation indicating the dependence of $q$ and $d$ on the money balances of the buyer has been suppressed. $\tau_{i, c}$ is the transaction cost associated with using currency $i$, which is different from the invoice currency $c$. We set $\tau_{c, c}$ equal to zero.

The equilibrium quantity of goods and currency exchanged will depend on whether the various currency constraints bind or not. Due to the presence of transaction costs associated with the non-invoice currency, there is a natural ordering procedure that will be used. First, the buyer uses all possible balances of the invoice currency. If the constraint is binding, she then uses another currency. If the balances are still not sufficient, she uses some of the third currency as well.

\footnotetext{
${ }^{27}$ Note that the average for the $R O W$ does not matter again.
} 


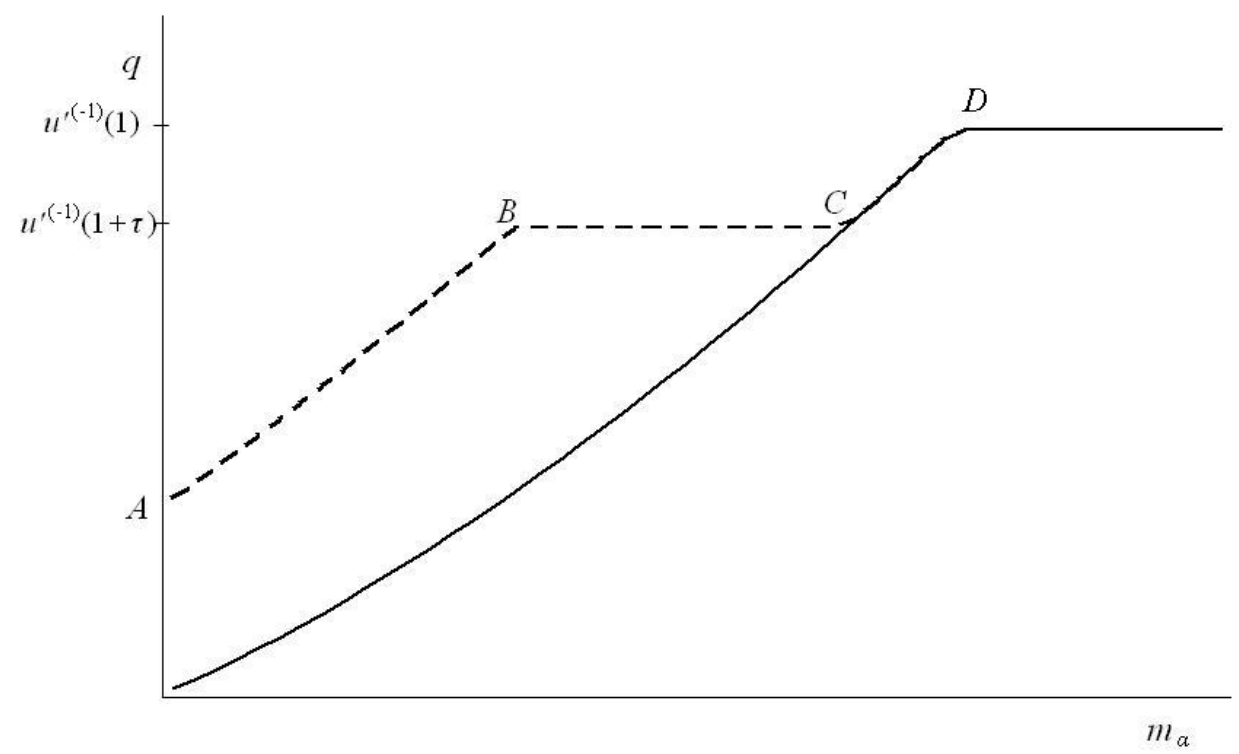

Figure 2: Quantity traded as a function of balances in currency- $\alpha$

If the constraint of the invoice currency does not bind, then the efficient quantity, $q^{*}$, is exchanged. On the other hand, if any of the non-invoice currencies is used and the constraint on that currency is non-binding, we will have

$$
u^{\prime}\left(\bar{q}_{c}^{i, j}\right)=1+\tau_{c^{\prime}, c}
$$

The existence of transaction costs introduces a wedge such that, even if the constraint on the non-invoice currency is non-binding, trade is not carried out at the efficient point, i.e. $u^{\prime}>1$. As a result, there exists a region of $q$ between $u^{\prime(-1)}(1+\tau)$ and $u^{\prime(-1)}(1)$ where the non-invoice currencies are not used, despite the fact that the invoice constraint is binding.

Figure 2 shows the implications of the transaction costs on the quantities traded. For the purpose of illustration, let's say we only have two currencies $\alpha$ and $\beta$ and that trade is invoiced in $\alpha$. The solid line in the figure gives the relationship between $q$ and $m_{\alpha}$ if $m_{\beta}=0$. This is the same relationship under the baseline model. The quantity exchanged increases until we reach the point where $q=q^{*}=u^{\prime(-1)}(1)$. After this point, the currency constraint is not binding, and the quantity traded is not a function of money balances. 
The dashed line in Figure 2 shows the relationship between $q$ and $m_{\alpha}$ if $m_{\beta}>0$. From point $A$ to point $B$, the currency constraint on both currencies are binding and so quantity is an increasing function of balances in currency $\alpha$. At point $B$, the constraint on currency- $\beta$ no longer binds and we are at the constrained efficient quantity where $\bar{q}=u^{\prime(-1)}(1+\tau)$. Between points $B$ and $C$, more of currency- $\alpha$ is used and less of $\beta$, but the quantity traded is still constant at $\bar{q}$. At point $C$, balances in currency $\alpha$ are sufficiently large that the quantity traded using only currency- $\alpha$ is larger than $\bar{q}$. Therefore, between points $C$ and $D$, only currency $\alpha$ is used despite the fact that we have balances in currency $\beta$.

The location of point $B$ depends on the quantity of balances in currency $\beta$. If we had sufficient balances, such that, even at $m_{\alpha}=0$, the currency constraint on currency $\beta$ was not binding, point $B$ will be at the point $(0, \bar{q})$. Lower balances of currency $\beta$ will move the point $B$ in a straight line to the right until it coincides with point $C$ when $m_{\beta}=0$.

Returning to the problem at hand, if all three constraints bind, the quantity exchanged is given by

$$
\phi^{\alpha} m_{\alpha}^{i}+\phi^{\beta} m_{\beta}^{i}+\phi^{\gamma} m_{\gamma}^{i}=\frac{u^{\prime}\left(q_{c}^{i, j}\right) q_{c}^{i, j}+u\left(q_{c}^{i, j}\right)-\left(\tau_{\alpha, c} \phi^{\alpha} m_{\alpha}^{i}+\tau_{\beta, c} \phi^{\beta} m_{\beta}^{i}+\tau_{\gamma, c} \phi^{\gamma} m_{\gamma}^{i}\right)}{u^{\prime}\left(q_{c}^{i, j}\right)+1}
$$

As opposed to the optimal invoicing behavior of agents in the baseline model, the invoicing pattern in this model will be taken as exogenous. Since we maintain the restriction that all domestic trade be carried out in domestic currency, optimal invoicing in this model will lead to all invoicing taking place in the currency of the importer to minimize transaction costs. While this is optimal within the model, we do not observe this invoicing behavior in the data. If anything, it is usually the currency of the exporter that is predominantly used (See Grassman (1973)). The divergence between the model and reality is due to a simplistic approach that we have taken in modeling the costs faced by the producer. More elaborate models of the invoicing of trade (Bachetta and Van Wincoop (2005) and Goldberg and Tille (2005)) show that other considerations that the seller faces, such as the denomination of factor costs in domestic currency, play a role in determining the invoicing currency. Rather than incorporating ad-hoc transaction costs for the seller, we just take the currency invoicing as exogenous and study the outcomes. ${ }^{28}$

\footnotetext{
${ }^{28}$ Note that any invoicing pattern can be supported as a Nash equilibrium where the seller decides on
} 
The definition of equilibrium, therefore, changes. An equilibrium in this economy is now quantities in the centralized market, quantities in the decentralized market, distribution of money holdings, and value functions such that, given prices and given an invoicing pattern, value functions and quantities in the centralized market solve (2) and (22), quantities in the decentralized market solve the symmetric bargaining problem as stated in (19) and the markets for money balances and homogenous goods clear. As in the baseline model, we will be restricting ourselves to stationary equilibria.

Based on the setup above, we can write the value function for an agent from country $i$ as she enters the decentralized market as

$$
\begin{aligned}
V^{i}\left(M_{t}^{i} ; I_{t}^{i}\right)= & \sum_{j} \sum_{c} \mu_{i j} \sigma s_{c}^{i j} b_{c}^{i j}\left\{u\left(q_{c}^{i, j}\right)+W\left(M^{i}-D_{c}^{i} ; I_{t}^{i}\right)-\tau_{c} D_{c}^{i}\right\} \\
& +\mu_{i j} \sigma s_{c}^{j i} b_{c}^{j i} \int\left\{-q_{c}^{j, i}+W\left(M^{i}+D_{c}^{j} ; I_{t}^{i}\right)\right\} d F_{t}^{j}\left(M_{t}^{j}\right) \\
& +\left(1-\sum_{j} 2 \mu_{i j} \sigma\right) W\left(M_{t}^{i} ; I_{t}^{i}\right)
\end{aligned}
$$

where the dependence of $q_{c}^{i, j}$ and $D_{c}^{i}$ on $M^{i}$ and $M^{j}$ is suppressed.

The decision problem faced by the agent in the centralized market in this model is exactly the same as that of the baseline model. The proof that buyers will use all their balances when conducting a transaction will involve verifying that $V_{m_{c, t+1}}<0$ in the regions of $M$-space where one or more currencies is in surplus. This is shown in the proposition below:

Proposition 3 Let the function $u$ be such that $V$ is strictly concave. Furthermore, let the transaction cost, $\tau$, be the same across all currencies. For all monetary equilibria in this model, the currency constraints for all currencies are binding.

\subsection{Quantitative estimates for the extension to the baseline model}

We now carry out a similar exercise as in the baseline model and compute the welfare gain/loss associated with different invoicing patterns. The transaction cost parameter for

the currency of invoice and the buyer says yes to that currency and no to any others. Of course, such an equilibrium is not sub-game perfect as the buyer's threat of saying no is not credible should the seller deviate from her equilibrium currency of invoice. 
Table 3

Welfare Changes in Extension Model

(relative to Equilibrium I, \% of consumption)

\begin{tabular}{cccc}
\multicolumn{4}{c}{$g_{\alpha}=g_{\beta}=g_{\beta}=.03$} \\
\hline \hline & $\tau=.01$ & $\tau=.05$ & $\tau=.10$ \\
\cline { 2 - 4 } & Eqm III & Eqm III & Eqm III \\
\hline $1-\Delta_{U S}$ & 0 & 0.01 & 0.01 \\
$1-\Delta_{E U R}$ & 0.03 & 0.13 & 0.26 \\
$1-\Delta_{R O W}$ & 0 & 0 & 0 \\
\hline
\end{tabular}

each currency is assumed to be the same. We examine the welfare impact for three values of this parameter: .01, .05 and .10. The inflation rate is assumed to be the same for each country and we set the rate equal to $3 \%$. The results are presented in Table $3 .^{29}$

As we would expect, the magnitude of the welfare changes are increasing with the size of the transaction costs. However, even at a transaction cost of $10 \%$, the magnitudes are much smaller than in the baseline model. In all the scenarios computed in Table 3, none of the agents hold balances in other currencies other than their own in equilibrium. Agents prefer to pay the transaction cost in the event that trade is invoiced in a different currency rather than hold balances in that currency. As a result, countries do not obtain any seignorage benefits from external money demand. The lack of seignorage benefits results in no change in welfare as move from Equilibrium II to Equilibrium III. Therefore, only results from Equilibrium III are shown. Furthermore, as the US does not experience any loss in seignorage revenues, its residents experience a welfare improvement as we move from Equilibrium I to Equilibrium II since the countervailing effect of a loss in seignorage revenues that we saw in the baseline model is no longer present. Seignorage effects will be present if we increase the transaction costs to the point that the benefit of holding some foreign balances outweigh the costs. Under the current parameterizations, agents in the Euro area will start to hold US dollars at $\tau=0.5$.

Transaction costs have two effects in this model. Apart from the direct effect of reducing welfare anytime a non-invoice currency is used, they also have an indirect effect in terms

\footnotetext{
${ }^{29}$ The use of different inflation rates along the line of the exercise carried out in the baseline model does not significantly change the results and so is not presented.
} 
of the allocation of resources towards money balances. Higher transaction costs diverts resources to consumption in the centralized market and away from money balances as it reduces the value of the money. These effects can be seen in the results in Table 3. Despite the fact that agents from the US never directly pay any transaction costs in all the equilibria, they still experience a welfare gain in moving to Equilibrium III. The welfare gain here comes from the removal of the distortion due to transaction costs faced by agents in the Euro area in Equilibrium I.

\section{Discussion and conclusion}

This paper has delivered new insights into the benefits for a country to have its currency widely used. Apart from the usual benefits associated with seignorage, the model has brought attention to a new channel that operates through the terms of trade. As more people use the domestic currency, its value in terms of the quantity of goods that can be purchased for a unit of the currency increases. The quantitative exercise carried out in this paper has shown that such gains can be significant.

In this section, we discuss two important aspects of the model that did not receive full attention earlier. The first is a discussion of how currencies in the model become international currencies, while the second is regarding the implications associated with the restriction on domestic trade invoicing.

\subsection{What makes a currency international?}

In this paper, we have utilized a liberal definition of an international currency. Any currency that is used in an international transaction is termed an international currency. ${ }^{30}$ A currency, therefore, becomes international if sellers decide to use it to invoice their international transactions. The factors that influence the choice of the seller are threefold: the behavior of other sellers, the relative size of the trading partner (as proxied by $\mu_{i i}$ ) and the inflation rate of the currency.

The behavior of other sellers introduces an externality into the invoicing decision of a particular seller. The surplus that accrues to invoicing in a given currency increases if

\footnotetext{
${ }^{30}$ Some authors use a more restrictive definition where a currency is only an international currency if it is used in an international transaction where the issuing country is not one of the counterparties in the trade.
} 
other sellers invoice in that currency too. These network externalities introduce multiple equilibria and inertia in the choice of an international currency.

The behavior of other sellers, however, cease to matter in trades with large countries. In trades with a large enough country, it becomes strictly dominant to invoice one's trade in the currency of that country. In the calibration exercise carried out in section 5, for example, it was strictly dominant to invoice trades with the US in the US dollar regardless of the invoicing behavior of the other countries. As such, under that calibration of the parameters, it is not possible for the euro to become the only international currency the way that the US dollar is in Equilibrium I. The euro can only achieve this status if the relative size of the US decreases or if the share of US trade with the rest of the world increases.

The behavior of other sellers will also not matter in cases where the inflation rate of a currency is very high. The higher the inflation rate, the lower the seller's surplus associated with transactions invoiced in that currency.

\subsection{Restriction on domestic trade invoicing}

A key restriction that is imposed through the paper is that domestic trade has to be invoiced in the domestic currency. As noted in the paper, this precludes the study of the "dollarization" phenomenon where foreign currencies are used as media of exchange in domestic transactions. More importantly for this paper, this restriction has implications for the welfare computations. Without this restriction, agents in the model will optimally use only one currency for all their trades. It may not be their domestic currency or the currency with the lowest inflation rate, but the distortion associated with agents holding balances in multiple currencies will no longer be there. Any welfare implications will therefore just be associated with seignorage transfers.

In practice, however, the restriction on domestic trade invoicing is a reasonable assumption especially for developed economies. An implication of this exercise, then, is that such restrictions in practice can be costly. Having said that, an important objective for future research is to provide a deeper rationale for endogenous multiple currencies. This is an important area for research and the output will contribute to the literature on optimum currency areas that originated with the works of Mundell (1961) and McKinnon (1963). 


\section{Appendix}

In this section, we provide the complete proofs for all the Lemmas and Propositions referenced to in the text.

\subsection{Proofs}

Lemma 1 For all equilibria, $V_{m_{c, t+1}^{i}}=\left[\mu_{c}^{i} \sigma u^{\prime}\left(q_{c, t+1}^{i}\right) q_{c, t+1}^{i^{\prime}}+\left(1-\mu_{c}^{i} \sigma\right) \phi_{t+1}^{i} e_{i / c, t+1}\right]$ if $m_{c, t+1}^{i}<m_{c, t+1}^{i *}$ and $V_{m_{c, t+1}^{i}}=\phi_{t+1}^{i} e_{i / c, t+1}$ for $m_{c, t+1}^{i} \geq m_{c, t+1}^{i *}$ where $\mu_{c}^{i}=\sum_{j} \mu_{i j} s_{c}^{i j} b_{c}^{i j}$.

Proof. Using equation (5) and the result that quantities exchanged do not depend on the money balances of the seller, we can rewrite equation (4) as

$$
\begin{aligned}
V^{i}\left(M_{t}^{i} ; I_{t}^{i}\right)= & \sum_{j} \sum_{c} \mu_{i j} \sigma s_{c}^{i j} b_{c}^{i j}\left[u\left(q_{c}^{i}\left(m_{c, t}^{i}\right)\right)-\phi_{t}^{i} e_{i / c} d_{c}^{i}\left(m_{c, t}^{i}\right)\right] \\
& +\mu_{i j} \sigma s_{c}^{j i} b_{c}^{j i} \int\left[-q_{c}^{j}\left(m_{c, t}^{j}\right)+\phi_{t}^{i} e_{i / c} d_{c}^{j}\left(m_{c, t}^{j}\right)\right] d F\left(m_{c, t}^{j}\right) \\
& +W\left(M_{t}^{i} ; I_{t}^{i}\right)
\end{aligned}
$$

So, we have that $V_{m_{c, t}^{i}}=\sum_{j} \mu_{i j} \sigma s_{c}^{i j} b_{c}^{i j}\left[u^{\prime} q^{\prime}-\phi_{t}^{i} e_{i / c} d_{c}^{i^{\prime}}\right]+\phi_{t}^{i} e_{i / c, t}$.

If $m_{c, t}^{i} \geq m_{c, t}^{i *}$, we have that $q^{\prime}=d^{\prime}=0$ from the bargaining solution in (8) and (9). If $m_{c, t}^{i}<m_{c, t}^{i *}$, then the currency constraint binds and $d^{\prime}=1$ and $q$ is a function of $m_{c, t}^{i}$ from equation (10) so $q^{\prime}=\frac{\phi_{t}^{i} e_{i / c, t}}{z^{\prime}(q)}$. This relationship holds for all $t$ and so holds for $t+1$ as well. Defining $\mu_{c}^{i}$ as $\sum_{j} \mu_{i j} s_{c}^{i j} b_{c}^{i j}$ gives us the result.

Lemma 2 For all monetary equilibria, $m_{c, t}^{i}<m_{c, t}^{i *}$ unless $\left(\frac{1}{1+g_{c, t}}\right)=\frac{1}{\delta}$.

Proof. From equation (4), we have that

$$
V_{m_{c, t+1}^{i}}\left(M_{t}^{i} ; I_{t}^{i}\right)=-\phi_{t}^{c}+\delta\left[\mu_{c}^{i} \sigma u^{\prime} q^{\prime}-\mu_{c}^{i} \sigma \phi_{t+1}^{c} d^{\prime}+\phi_{t+1}^{c}\right]
$$

If the constraint does not bind, $q^{\prime}=d^{\prime}=0$ and we have

$$
V_{m_{c, t+1}^{i}}=-\phi_{t}^{c}+\delta \phi_{t+1}^{c} \leq 0
$$

where the inequality is assumed for there to be a monetary equilibrium with finite balances. 
We now see how $V_{m_{c, t+1}^{i}}$ behaves as $m_{c, t+1}^{i} \rightarrow m_{c, t+1}^{i *}$ from below.

$$
V_{m_{c, t+1}^{i}}=-\phi_{t}^{c}+\delta \phi_{t+1}^{c}+\delta \mu_{c}^{i} \sigma \phi_{t+1}^{c}\left[\frac{u^{\prime}}{z^{\prime}}-1\right]
$$

As $m_{c, t+1}^{i} \rightarrow m_{c, t+1}^{i *}$, we have

$$
V_{m_{c, t+1}^{i}} \rightarrow-\phi_{t}^{c}+\delta \phi_{t+1}^{c}+\delta \mu_{c}^{i} \sigma \phi_{t+1}^{c}\left[\frac{4}{8-u^{\prime \prime}(u-q)}-1\right]
$$

Since $u>q$, we have that $V_{m_{c, t+1}^{i}}<0$ as we approach $m^{*}$. Therefore, in any monetary equilibrium, $m_{c, t+1}^{i}<m_{c, t+1}^{i *}$.

Proposition 1 Let the seller's surplus of invoicing in currency $c$ be denoted as $S^{S} \equiv$ $-q_{c}^{j}+W\left(M^{i}+I_{c} \cdot D^{j}\right)$. We then have

(i) $\left.\frac{\partial S^{S}}{\partial q}\right|_{q<q^{*}}>0$

(ii) $\frac{\partial q_{c}^{i}}{\partial \mu_{c}^{i}}>0$

(iii) $\frac{\partial q_{c}^{i}}{\partial g_{c}}<0$

Proof. Let's denote the seller's surplus as

$$
S^{S}=-q_{c}^{i}+\phi_{t}^{c} m_{c}^{i}
$$

Using equation (10), we can then rewrite the surplus as $S^{S}\left(q_{c}^{j}\right) \equiv-q_{c}^{j}+z\left(q_{c}^{j}\right)$.

(i) We then have that $S^{\prime}\left(q_{c}^{j}\right)=-1+z^{\prime}\left(q_{c}^{j}\right)$. Therefore, $S(\cdot)$ is increasing iff $z^{\prime}\left(q_{c}^{j}\right)>1$.

From equation (10), we have

$$
z\left(q_{c}^{j}\right)=\frac{u^{\prime}(q)(q)+u(q)}{u^{\prime}(q)+1}
$$

We can then rewrite the condition $z^{\prime}\left(q_{c}^{j}\right)>1$ as

$$
\left(u^{\prime}\right)^{2}-u^{\prime \prime}[u-q]>1
$$

From Lemma 2, we have that $q_{c}<q_{c}^{*}$. Since $u^{\prime \prime}<0$ and $c(q)$ is linear, we have that $u>q$ and $u^{\prime}>1$. Using these results, we have that

$$
\left(u^{\prime}\right)^{2}-u^{\prime \prime}[u-q]>\left(u^{\prime}\right)^{2}>1
$$

Therefore, $S^{S}$ is increasing in $q$ in the region of interest. 
(ii) From equation (13), we have that

$$
1=\delta\left[\mu_{c}^{i} \sigma \frac{u^{\prime}}{z^{\prime}}+1-\mu_{c}^{i} \sigma\right] \xi \text { where } \xi=\left(\frac{1}{1+g_{c, t}}\right)
$$

Using the implicit function theorem, we get that

$$
\frac{\partial q_{c}^{i}}{\partial \mu_{c}^{i}}=-\frac{u^{\prime} / z^{\prime}-1}{\mu_{c}^{i}\left[\frac{z^{\prime} u^{\prime \prime}-u^{\prime} z^{\prime \prime}}{\left(z^{\prime}\right)^{2}}\right]}
$$

From (13), we have that

$$
\frac{u^{\prime}}{z^{\prime}}=1+\frac{1-\delta \xi}{\delta \xi \mu \sigma}
$$

The numerator of the fraction on the right-hand side is nonnegative as long as $\xi \leq \frac{1}{\delta}$. However, in any equilibrium, we must have that $\xi \leq \frac{1}{\delta} \cdot 31$ Therefore, we know that $u^{\prime} \geq z^{\prime}$ so we have that the numerator is nonnegative. From the condition requiring $V(\cdot)$ to be concave, we know that $\frac{z^{\prime} u^{\prime \prime}-u^{\prime} z^{\prime \prime}}{\left(z^{\prime}\right)^{2}}<0$. Therefore, we have that $\frac{\partial q_{c}^{i}}{\partial \mu_{c}^{i}} \geq 0$.

(iii) Using the implicit function theorem on equation (13) again, we have

$$
\frac{\partial q}{\partial g}=\frac{1}{\delta \sigma \mu_{c}^{i}\left[\frac{z^{\prime} u^{\prime \prime}-u^{\prime} z^{\prime \prime}}{\left(z^{\prime}\right)^{2}}\right]}<0
$$

from the proof in part (ii).

Proposition 2 As we move from an equilibrium where currency $c$ is more internationally used to one where it is less internationally used, the price level in the issuing country increases.

Proof. When we move to an equilibrium where currency $c$ is less internationally used, we will have a lower $\mu_{c}^{i}$ for at least one country $i$. Since $\frac{\partial z}{\partial q}>0$ and $\frac{\partial q}{\partial \mu_{c}}>0$ from Proposition 1, we will have that $\frac{\partial \phi^{c}}{\partial \mu_{c}}>0$. Therefore, as we move to an equilibrium where $c$ is less internationally used, $\phi^{c}$ will decrease implying that the price level will increase.

\footnotetext{
${ }^{31}$ See Lemma 2.
} 
Proposition 3 Let the function $u$ be such that $V$ is strictly concave. Furthermore, let the transaction cost, $\tau$, be the same across all currencies. For all monetary equilibria in this model, the currency constraints for all currencies are binding.

Proof. The basic idea behind the proof will be to show that the value function is downward sloping at different "threshold values". The threshold values are the following. First, when we have sufficient balances to achieve the efficient allocation with just the invoice currency, $m_{c}^{*}$. Second, when we have enough of the invoice currency to reach the constrained efficient allocation, $\bar{q}=u^{(-1)}(1+\tau)$ just by using the invoice currency, $m_{c}^{* *}$, and third, when we can achieve the constrained efficient allocation in trades not invoiced in c by using currency $c, m_{c}^{* * *}$. The complication is that $m_{c}^{* * *}$ will depend on the balances of the other currencies so we have to check various cases to ensure that the value function is downward sloping in all of these cases. In each case, we will verify that

$$
V_{m_{c, t+1}}=-\phi_{t}^{c}+\delta\left\{\sum_{c^{\prime}} \mu_{c^{\prime}} \sigma\left[u^{\prime} \frac{\partial q_{c^{\prime}}}{\partial m_{c}}-\sum_{c^{\prime \prime}}\left(1+\tau_{c^{\prime}, c}\right) \phi_{t+1}^{c^{\prime \prime}} \frac{\partial d_{c^{\prime \prime}, c^{\prime}}}{\partial m_{c}}\right]+\phi_{t+1}^{c}\right\}
$$

is negative as we approach each respective threshold level from below.

Before we begin, we note that $m_{c}^{*}>m_{c}^{* *}$ since $q>\bar{q}$. Also, we can show that

$$
\phi^{c} m_{c}^{* * *}=\frac{(1+\tau) u(\bar{q})+\bar{q}}{\left(1+(1+\tau)^{2}\right)}-\frac{(2+\tau)}{\left(1+(1+\tau)^{2}\right)} \phi^{c^{\prime}} m_{c^{\prime}}-\phi^{c^{\prime \prime}} m_{c^{\prime \prime}}
$$

for trades invoiced in $c^{\prime}$. We can see that $m_{c}^{* * *}$ is a decreasing function of balances in currencies $c^{\prime}$ and $c^{\prime \prime}$. It can be shown that $m_{c}^{* *}>m_{c}^{* * *}(0,0)$.

We first verify that $V_{m_{c, t+1}}<0$ when $m_{c}>m_{c}^{*} .{ }^{32}$ When balances in the other currencies $c^{\prime}$ and $c^{\prime \prime}$ are such that $m_{c^{\prime}}>m_{c^{\prime}}^{* *}$ and $m_{c^{\prime \prime}}>m_{c^{\prime \prime}}^{* *}$, no currency other than the invoice currency is used in all transactions. Therefore, $\frac{\partial q_{c^{\prime}}}{\partial m_{c}}=\frac{\partial d_{c^{\prime \prime}, c^{\prime}}}{\partial m_{c}}=0$ for all transactions. We then have that $V_{m_{c, t+1}}=-\phi_{t}^{c}+\delta \phi_{t+1}^{c}$ which has to be negative for a monetary equilibrium with finite balances to exist.

Now, suppose that balances in one of the currencies, say $c^{\prime}$, is lower than $m_{c^{\prime}}^{* *}$. Since $m_{c}>m_{c}^{*}>m_{c}^{* * *}(0,0)$, we know that there are sufficient balances in $c$ such that the constrained efficient allocation is achieved. So, once again, we have that $V_{m_{c, t+1}}=-\phi_{t}^{c}+\delta \phi_{t+1}^{c}$ which is negative.

\footnotetext{
${ }^{32}$ We suppress the time subscript on currency balances to prevent clutter. It will be understood that money balances are referring to period $t+1$. For the inverse-price variable, we will continue to use time subscripts to avoid confusion.
} 
We next verify that $V_{m_{c, t+1}}<0$ when $m_{c} \rightarrow m_{c}^{*}$. We first check the case where $m_{c^{\prime}}>m_{c^{\prime}}^{* *}$ and $m_{c^{\prime \prime}}>m_{c^{\prime \prime}}^{* *}$. We then have that

$$
V_{m_{c, t+1}}=-\phi_{t}^{c}+\delta \mu_{c} \sigma \phi^{c}\left[\frac{2}{2-u^{\prime \prime}(-q+R M)}-1\right]
$$

where $R M$ is the sum of all the real money balances held by the buyer. Since the seller is getting a positive surplus, we have that $-q+R M>0$. Therefore, $\left[\frac{2}{2-u^{\prime \prime}(-q+R M)}-1\right]<0$ and $V_{m_{c, t+1}}<0$. Now, we consider the case that balances in one of the currencies, say $c^{\prime}$, is lower than $m_{c^{\prime}}^{* *}$. As $m_{c}$ approaches $m_{c}^{*}$ from below, we know that there will be sufficient balances in c such that the constrained efficient allocation is achieved. So, we will have the same result as above and $V_{m_{c, t+1}}<0$.

We next verify that $V_{m_{c, t+1}}<0$ when $m_{c} \rightarrow m_{c}^{* *}$. As usual, we first check the case where $m_{c^{\prime}}>m_{c^{\prime}}^{* *}$ and $m_{c^{\prime \prime}}>m_{c^{\prime \prime}}^{* *}$. We then have that

$$
V_{m_{c, t+1}}=-\phi_{t}^{c}+\delta \mu_{c} \sigma \phi^{c}\left[\frac{(2+\tau)}{2(1+\tau)-u^{\prime \prime}(-q+R M)}-1\right]<0
$$

If instead, balances in one of the currencies, $c^{\prime}$, is lower than $m_{c^{\prime}}^{* *}$, we will still get the same result as the one above since $m_{c}^{* *}>m_{c}^{* * *}(0,0)$.

Finally, we verify that $V_{m_{c, t+1}}<0$ when $m_{c} \rightarrow m_{c}^{* * *}\left(m_{c^{\prime}}, m_{c^{\prime \prime}}\right)$. This case is only relevant when $m_{c^{\prime}}<m_{c^{\prime}}^{* *}$ and $m_{c^{\prime \prime}}<m_{c^{\prime \prime}}^{* *}$. For trades invoiced in currency $c^{\prime}$, we will not use currency $c$ if balances in currency $c^{\prime \prime}$ are sufficient. The relevant case, therefore, is when the other two constraints are binding. ${ }^{33}$ We then have

$$
\begin{aligned}
V_{m_{c, t+1}}= & -\phi_{t}^{c}+\delta \mu_{c} \sigma \phi^{c}\left[\frac{(2+\tau)}{2(1+\tau)-u^{\prime \prime}(-q+R M)}-1\right] \\
& +\delta \sum_{k=c^{\prime}, c^{\prime \prime}} \mu_{k} \sigma \phi^{c}\left[\frac{2(1+\tau)}{2(1+\tau)-u^{\prime \prime}(-q+R M)}-(1+\tau)\right]<0
\end{aligned}
$$

Therefore, we have that $m_{c}<m_{c}^{* * *}\left(m_{c^{\prime}}, m_{c^{\prime \prime}}\right)$. Since $V$ is strictly concave, verification at the regions above is sufficient to show that the currency constraint will be binding on all transactions.

\footnotetext{
${ }^{33}$ We do not consider the case where a buyer splits his payment between currencies.
} 


\subsection{Model using annual data}

In this subsection, we present the quantitative results of the baseline model using annual instead of quarterly data as a form of a robustness test. The variables are all taken from the same sources as mentioned in the main text. The recalibrated values for $(\eta, B)$ is $(0.7132$, 3.0774). We use a value of 0.5 for $\sigma$ and 0.9615 for $\delta$. The results for the annual model, as presented in Table 4, have similar magnitudes to that of the quarterly model.

Table 4

Welfare Changes in Consumption Equivalent Terms Relative to Equilibrium I (\%)

\begin{tabular}{ccccccc}
\hline \hline & \multicolumn{2}{c}{$g_{\alpha}=g_{\beta}=.03$} & \multicolumn{2}{c}{$g_{\alpha}=.045 ; g_{\beta}=.062$} & \multicolumn{2}{c}{$g_{\alpha}=.03 ; g_{\beta}=.02$} \\
& \multicolumn{2}{c}{$g_{\gamma}=.03$} & \multicolumn{2}{c}{$g_{\gamma}=.10$} & \multicolumn{2}{c}{$g_{\gamma}=.05$} \\
\cline { 2 - 7 } & Eqm II & Eqm III & Eqm II & Eqm III & Eqm II & Eqm III \\
\hline $1-\Delta_{U S}$ & -0.36 & -1.10 & -0.50 & -1.40 & -0.35 & -1.07 \\
$1-\Delta_{E U R}$ & 1.29 & 1.98 & 1.51 & 2.37 & 1.28 & 1.86 \\
$1-\Delta_{R O W}$ & 0 & 0 & 0.01 & -0.02 & 0.02 & 0.04 \\
\hline
\end{tabular}




\section{References}

Aruoba, S. B., And R. Wright (2003): "Search, Money and Capital: A Neoclassical Dichotomy," Journal of Money, Credit and Banking, 35(6), 1085-1105.

Bacchetta, P., And E. van Wincoop (2005): "A Theory of the Currency Denomination of International Trade," Journal of International Economics, 67(2), 295-319.

Chinn, M., and J. Frankel (2005): "Will the Euro Eventually Surpass the Dollar as Leading International Reserve Currency," NBER Working Papers 11510, National Bureau of Economic Research, Inc.

Cohen, B. (1971): The Future of Sterling as an International Currency. St. Martin's Press.

Devereux, M. B., And S. Shi (2005): "Vehicle Currency," Working Paper.

Dowd, K., and D. Greenaway (1993): "Currency Competition, Network Externalities and Switching Costs: Towards an Alternative View of Optimum Currency Areas," Economic Journal, 103(420), 1180-89.

Eichengreen, B. (2005): "Sterling's Past, Dollar's Future: Historical Perspectives on Reserve Currency Competition," NBER Working Papers 11336, National Bureau of Economic Research, Inc.

Goldberg, L. S., And C. Tille (2005): "Vehicle Currency Use in International Trade," NBER Working Papers 11127, National Bureau of Economic Research, Inc.

Grassman, S. (1973): "A fundamental symmetry in international payment patterns," Journal of International Economics, 3(2), 105-116.

Hartmann, P. (1997): "Does Reuters Spreads Reflect Currencies Differences in Global Trading Activity?," Discussion paper, Financial Markets Group.

International Monetary Fund (Various years): International Financial Statistics.

International Monetary Fund (Various years): Direction of Trade Statistics.

Kannan, P. (2006): "Network Externalities and the Decline of the Sterling as an International Currency," Working Paper. 
Kindleberger, C. (1981): International Money. George Allen and Unwin.

Kiyotaki, N., and R. Wright (1989): "On Money as a Medium of Exchange," Journal of Political Economy, 97(4), 927-954.

- (1993): "A Search-Theoretic Approach to Monetary Economics," American Economic Review, 83(1), 63-77.

Kocherlakota, N. R. (1998): "Money Is Memory," Journal of Economic Theory, 81(2), $232-251$.

Krugman, P. (1980): "Vehicle Currencies and the Structure of International Exchange," Journal of Money, Credit and Banking, 12(3), 513-526.

— (1984): "The International Role of the Dollar: Theory and Prospect," in Exchange Rate Theory and Practice, ed. by J. Bilson, and R. Marston, pp. 261-278. University of Chicago Press, Chicago.

Lagos, R., and R. Wright (2005): "A Unified Framework for Monetary Theory and Policy Analysis," Journal of Political Economy, 113(3), 463-484.

LuCAS, R. E. (1987): Models of Business Cycles.

Matsuyama, K., N. Kiyotaki, and A. Matsui (1993): "Toward a Theory of International Currency," Review of Economic Studies, 60(2), 283-307.

McKinnon, R. (1979): Money in International Exchange: The Convertible Currency System. Oxford University Press.

McKinnon, R. I. (1963): "Optimum Currency Areas," American Economic Review, pp. $717-725$.

Mundell, R. A. (1961): "A Theory of Optimum Currency Areas," American Economic Review, 51, 509-517.

Portes, R., And H. Rey (1998): "The Emergence of the Euro as an International Currency," Economic Policy, pp. 307-343.

Rey, H. (2001): "International Trade and Currency Exchange," Review of Economic Studies, pp. 443-464. 
Trejos, A., And R. Wright (1996): "Search-theoretic models of international currency," Proceedings, (May), 117-132.

Wallace, N. (2001): "Whither Monetary Economics?," International Economic Review, $42(4), 847-869$.

World BANK (online): World Development Indicators.

Wright, R., And A. Trejos (2001): "International Currency," Advances in Macroeconomics, 1(1), Article 3. 